Article

\title{
Earth Observation and Cloud Computing in Support of Two Sustainable Development Goals for the River Nile Watershed Countries
}

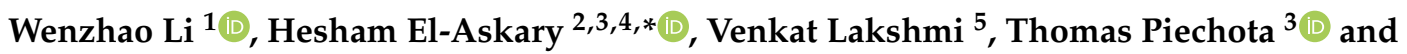 \\ Daniele Struppa ${ }^{3}$ \\ 1 Computational and Data Sciences Graduate Program, Schmid College of Science and Technology, \\ Chapman University, Orange, CA 92866, USA; li276@mail.chapman.edu \\ 2 Center of Excellence in Earth Systems Modeling and Observations, Chapman University, Orange, \\ CA 92866, USA \\ 3 Schmid College of Science and Technology, Chapman University, Orange, CA 92866, USA; \\ piechota@chapman.edu (T.P.); struppa@chapman.edu (D.S.) \\ 4 Department of Environmental Sciences, Faculty of Science, Alexandria University, Moharem Bek, \\ Alexandria 21522, Egypt \\ 5 Engineering Systems and Environment, University of Virginia, Charlottesville, VA 22904, USA; \\ vlakshmi@virginia.edu \\ * Correspondence: elaskary@chapman.edu
}

Received: 19 February 2020; Accepted: 23 April 2020; Published: 28 April 2020

\begin{abstract}
In September 2015, the members of United Nations adopted the 2030 Agenda for Sustainable Development with universal applicability of 17 Sustainable Development Goals (SDGs) and 169 targets. The SDGs are consequential for the development of the countries in the Nile watershed, which are affected by water scarcity and experiencing rapid urbanization associated with population growth. Earth Observation (EO) has become an important tool to monitor the progress and implementation of specific SDG targets through its wide accessibility and global coverage. In addition, the advancement of algorithms and tools deployed in cloud computing platforms provide an equal opportunity to use EO for developing countries with limited technological capacity. This study applies EO and cloud computing in support of the SDG 6 "clean water and sanitation" and SDG 11 "sustainable cities and communities" in the seven Nile watershed countries through investigations of EO data related to indicators of water stress (Indicator 6.4.2) and urbanization and living conditions (Indicators 11.3.1 and 11.1.1), respectively. Multiple approaches including harmonic, time series and correlational analysis are used to assess and evaluate these indicators. In addition, a contemporary deep-learning classifier, fully convolution neural networks (FCNN), was trained to classify the percentage of impervious surface areas. The results show the spatial and temporal water recharge pattern among different regions in the Nile watershed, as well as the urbanization in selected cities of the region. It is noted that the classifier trained from the developed countries (i.e., the United States) is effective in identifying modern communities yet limited in monitoring rural and slum regions.
\end{abstract}

Keywords: hydrology; impervious surface; Nile watershed; SDG; fully convolutional neural networks; Google Earth Engine; Google Cloud Platform; GRACE; CHIRPS; FLDAS; soil moisture; Landsat-8

\section{Introduction}

The Nile is a major north-flowing river passing through 11 countries in Northeastern Africa, and these countries from south to north are Tanzania, Uganda, Rwanda, Burundi, the Democratic Republic of the Congo, Kenya, Ethiopia, Eritrea, South Sudan, Republic of the Sudan and Egypt. 
With an estimated length ranging between $5499 \mathrm{~km}$ and $7088 \mathrm{~km}$, it is the longest river in Africa and widely regarded as the longest river in the world [1]. The Nile serves as the primary water source to downstream nations namely, Sudan and Egypt [2]. However, water stress/scarcity are expected because of limited water to meet the various irrigation needs of the Nile Basin nations, as well as hydraulic engineering projects among the countries such as hydropower dams being built in Sudan (Merowe dam), Ethiopia (Grand Renaissance dam) and Uganda (Karuma dam) and other stressors driven by climate change. It is noted that these projects will not reduce the tensions between countries but possibly introduce more challenges, bringing the uncertainty of the future economic development and regional stability. Additionally, the local water measurements of the Nile are outdated and limited for scientific studies. For example, the latest records of stations in the Global Runoff Data Centre (https://www.bafg.de/GRDC/EN/01_GRDC/grdc_node.html) dataset date back to 1984.

Countries in the Nile are undergoing rapid population growth and urbanization. Seven Nile Basin countries are expected to double their populations between 1995 and 2025 [3]. Most of the countries have agriculturally-based economies, and rapid population growth will further pressure natural resources and often contribute to environmental stress. The limited financial resources and technological abilities of the majority of these nations result in them being unable to properly take mitigation actions. Additionally, rapid urbanization is anticipated in the Nile countries due to the increasing movement of people from rural to urban areas associated with population growth and poverty. On the one hand, the rapid urbanization is driven by the labor migration and it possibly coincided with process of industrialization [4]. On the other hand, the unplanned urban regions often lack the infrastructure and institutions needed to supply adequate water and sanitation, as well as reliable housing and public transportation, in order to protect human and environmental health. The migrated populations form or join the low-income communities (slum urbanizations) that are especially impacted by inadequate environmental services and by water and air pollution. The situation is typical in the Nile countries, since the ongoing South Sudanese civil war has sent at least over 2 million people migrating to neighboring countries as refugees [5]. The uncontrolled growth (from 245,000 in 1956 to more than 7 million in 2012) of Sudan's capital Khartoum has resulted in 50\% of residents are living in informal and squatter settlements on the outskirts of the city [6].

On the historical 70th anniversary of the United Nations (UN) in September 2015, the heads of state and delegates gathered and adopted the 2030 Agenda for Sustainable Development [7]. This comprehensive sustainability framework was built on the historical experiences of human society and a shared expectation for the next 15 years. The 17 Sustainable Development Goals (SDGs) incorporate various social, economic, environmental, and developmental aspects, which consist of 169 targets and 230 indicators [8], and have been endorsed by all countries with respective national implementation plans for their different and very diverse development context. It can be concluded that the SDGs constitute a vast system that is complicated, diverse, dynamic, and interconnected, where success in achieving one goal is often linked to solving issues associated with other goals. However, according to SDG reports from the UN [9] and Chinese Academy of Sciences [10], the lack of accurate and timely data, as well as the lag in developing proper methodologies to process the data, has become a bottleneck that the full implementation of the 2030 SDGs will be hampered if these issues are not effectively resolved. Therefore, in order to achieve the SDGs and effectively assess their progress with the full strength of science, technology, and innovation (STI), the UN has established the "Technology Facilitation Mechanism" (TFM) [11]. Presently, a pressing priority of TFM is to make breakthroughs towards Tier II indicators (methods established but with poor data) and Tier III indicators (methods under development with either poor data or no data).

To support and track the progress in fulfilling SDGs, the UN suggested that Earth Observation (EO) and geo-spatial data should be utilized to mitigate the shortage of in-situ data availability [12]. EO provides reliable, updated and cost-effective data resources [13], which have been applied to monitor the SDG-related parameters from regional to global scales on a consistent and regular basis [14-18]. Nevertheless, the EO datasets are also characterized by massive quantity, multiple 
sources, multi-temporal, multi-dimensional heterogeneous structure, and high complexity. The study of EO data in support of SDGs, therefore, requires powerful computing capabilities and advanced analytical methods.

Recently, the advancement of cloud computing, including parallel computing, offer near unlimited computer processing capabilities, as well as free access to a large volume of EO data already stored on the remote cloud drives. There has been an emerging increase in high-performance cloud computing platforms, such as the National Aeronautics and Space Administration (NASA) Earth Exchange (NEX), Amazon Web Service (AWS) and Google Earth Engine (GEE) [19]. The GEE directly accesses the Google's cloud resources to undertake all the processing and analysis, which does not require large processing powers of computers or expensive software. It is characterized as an easily accessible and user-friendly front-end platform providing a convenient environment for interactive data representation and algorithm development. For instance, Donchyts et al. [20] employed the GEE for mapping global surface water changes over the past 30 years with a high spatial resolution $(30 \mathrm{~m})$, an effort that would not have been possible without the powerful processing and analytical capabilities from cloud computing. GEE is also widely used for environmental research in the Nile watershed and adjacent regions [14,21-25]. In particular, it is a promising tool that allows researchers from developing countries (e.g., Nile Basin countries) to have the same ability to undertake state-of-art studies as those in the most advanced nations. Considering the urgent situation of water data availability and urbanization stress in the Nile Basin countries, the EO and cloud computing evidently appear to be one of the priorities to help achieve the SDGs.

This paper demonstrates the intersection between EO, cloud computing and related technologies and demonstrates how they contribute to the assessment of two SDGs in the Nile watershed countries, namely SDG 6 "clean water and sanitation" and SDG 11 "sustainable cities and communities", with focus on the water stress situation and urbanization process. This is carried out through studying the water resources using multiple hydrological variables, as well as the change detection of the land cover in five major Nile Basin cities using advanced algorithms implemented on a cloud-computing platform.

\section{Materials and Methods}

\subsection{Study Area}

In this study, we investigate seven countries in the River Nile watershed, namely, Egypt, Sudan, South Sudan, Ethiopia, Uganda, Kenya and Tanzania, which totally occupy up to $97.91 \%$ of the areas of the watershed calculated from the shapefile accessed from the Nile Basin Initiative (https://www.nilebasin.org) (Table 1). Sudan has the biggest size (33.92\%) compared to other countries, while both South Sudan and Uganda have their entire territories within the watershed (left of Figure 1). In Section 2.2, we will study the water stress situation in the countries mentioned above. Furthermore, in Section 2.3, we will investigate the changes of impervious surface in five specific capital cities, over the recent years, in some of these countries. The five capital cities, in this region, targeted here are namely: Cairo, Khartoum, Juda, Addis Ababa and Kampala.

Table 1. The countries in the Nile watershed under investigation in this research.

\begin{tabular}{cccc}
\hline Country & Capital City & Calculated Area $\left.\mathbf{( k m}^{\mathbf{2}}\right)$ & Percentage \\
\hline Egypt & Cairo & $232,522.1$ & $8.98 \%$ \\
Sudan & Khartoum & $878,440.2$ & $33.92 \%$ \\
South Sudan & Juda & $638,825.2$ & $24.67 \%$ \\
Ethiopia & Addis Ababa & $360,680.9$ & $13.93 \%$ \\
Uganda & Kampala & $239,450.5$ & $9.25 \%$ \\
Kenya & Nairobi & $112,661.4$ & $4.35 \%$ \\
Tanzania & Dodoma & $72,724.7$ & $2.81 \%$ \\
\hline Nile watershed & N/A & $2,589,724.4$ & $97.91 \%$ \\
\hline
\end{tabular}




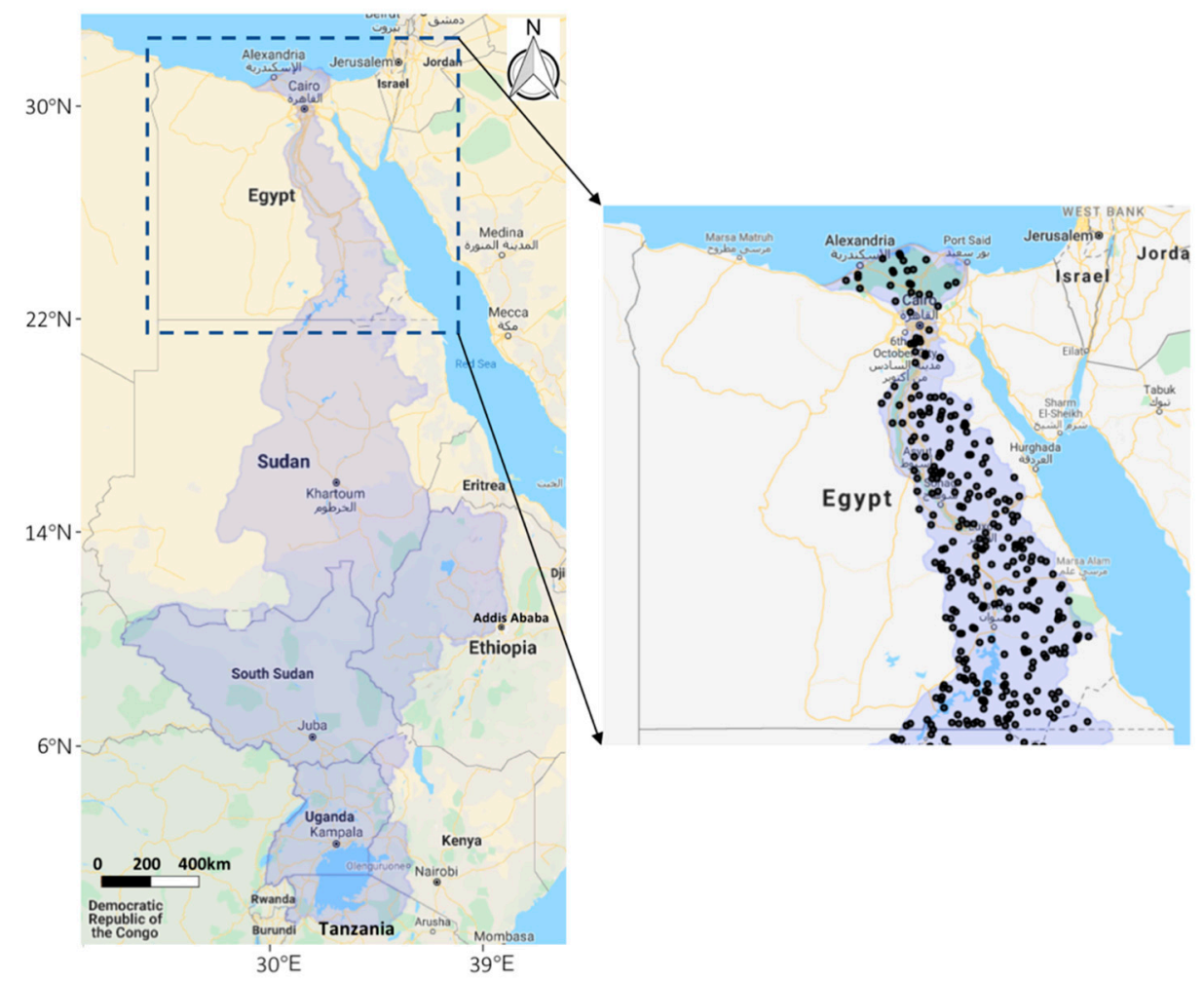

Figure 1. Left: the map of countries in the Nile watershed region and the selected capital cities (Cairo, Khartoum, Juba, Addis Ababa and Kampala) in this study. Right: sample points collected in Egypt.

\subsection{Data and Methods to Study Sustainable Development Goal (SDG) 6 Indicator on Water Stress}

Target 6.4 of SDG 6 is to "substantially increase water-use efficiency across all sectors and ensure sustainable withdrawals and supply of freshwater to address water scarcity and substantially reduce the number of people suffering from water scarcity." Its Indicator 6.4.2, "Level of water stress: freshwater withdrawal as a proportion of available freshwater resources", is explicitly used for monitoring water stress situations at the country level. This indicator (water stress) has been defined as the ratio percentage (\%) between total freshwater withdrawn (TFWW) by all major sectors and total renewable freshwater resources (TRWR), after having taken into account environmental water requirements (EFR). It is calculated with the following equation:

$$
\text { Water Stress }=\frac{\text { TFWW }}{\text { TRWR }- \text { EFR }} \times 100 \%
$$

A low level of water stress shows a situation where the combined withdrawal is marginal in proportion to the total renewable freshwater resources and has, therefore, little potential impact on the sustainability of the resources or on the potential competition between users. A high level of water stress indicates an opposite situation where the combined withdrawal represents a substantial share of the resources, with potentially larger impacts on the sustainability of the resources and potential situations of conflicts and competition between users, resulting in negative effects on economic development and food security. Since 1994, the Food and Agriculture Organization of the United Nations (FAO) has been monitoring the parameters of water stress through its global water information system, AQUASTAT [26]. Table 2 demonstrates the water stress indicator and related parameters of the Nile countries between 2007 and 2017 from AQUASTAT database (http://www.fao.org/nr/water/aquastat/main/index.stm). 
Table 2. The water stress and related parameters of countries in the Nile watershed.

\begin{tabular}{|c|c|c|c|c|c|c|c|c|c|c|c|}
\hline & \multicolumn{3}{|c|}{ Egypt } & \multicolumn{3}{|c|}{ Ethiopia } & \multicolumn{5}{|c|}{ Kenya } \\
\hline & 2007 & 2012 & 2017 & 2007 & 2012 & 2017 & \multicolumn{2}{|c|}{2007} & 2012 & \multicolumn{2}{|c|}{2017} \\
\hline $\mathrm{SW}_{\mathrm{P}}$ & 0.5 & 0.5 & 0.5 & 120 & 120 & 120 & \multicolumn{2}{|c|}{20.2} & 20.2 & \multicolumn{2}{|c|}{20.2} \\
\hline $\mathrm{GW}_{\mathrm{R}}$ & 0.5 & 0.5 & 0.5 & 20 & 20 & 20 & \multicolumn{2}{|c|}{3.5} & 3.5 & \multicolumn{2}{|c|}{3.5} \\
\hline Q OUT-Q $_{\text {IN }}$ & 0 & 0 & 0 & 18 & 18 & 18 & \multicolumn{2}{|l|}{3} & 3 & \multicolumn{2}{|c|}{3} \\
\hline IRWR & 1 & 1 & 1 & 122 & 122 & 122 & \multicolumn{2}{|c|}{20.7} & 20.7 & \multicolumn{2}{|c|}{20.7} \\
\hline TRESW & 55.5 & 55.5 & 55.5 & 0 & 0 & 0 & \multicolumn{2}{|c|}{10} & 10 & \multicolumn{2}{|c|}{10} \\
\hline $\mathrm{GW}_{\mathrm{IN}}$ & 1 & 1 & 1 & 0 & 0 & 0 & \multicolumn{2}{|l|}{0} & 0 & \multicolumn{2}{|c|}{0} \\
\hline ERWR & 56.5 & 56.5 & 56.5 & 0 & 0 & 0 & \multicolumn{2}{|l|}{10} & 10 & \multicolumn{2}{|c|}{10} \\
\hline TRSW & 56 & 56 & 56 & 120 & 120 & 120 & \multicolumn{2}{|c|}{30.2} & 30.2 & \multicolumn{2}{|c|}{30.2} \\
\hline TRGW & 1.5 & 1.5 & 1.5 & 20 & 20 & 20 & \multicolumn{2}{|c|}{3.5} & 3.5 & \multicolumn{2}{|c|}{3.5} \\
\hline TRWR & 57.5 & 57.5 & 57.5 & 122 & 122 & 122 & \multicolumn{2}{|c|}{30.7} & 30.7 & \multicolumn{2}{|c|}{30.7} \\
\hline EFR & 2.6 & 2.6 & 2.6 & 89.3 & 89.3 & 89.3 & \multicolumn{2}{|c|}{18.57} & 18.57 & & \\
\hline FSWW & - & NA & NA & - & - & - & - & & - & 3.50 & 016) \\
\hline FGWW & - & 7.5 & 6.5 & - & - & - & - & & - & 0.52 & 016) \\
\hline TFWW & - & 68.1 & 64.4 & 7.861(2005) & - & $10.55(2016)$ & $2.32(20$ & 03) & $3.218(2010)$ & 4.03 & 016) \\
\hline WS & - & 124 & 117.3 & $24.04(2005)$ & - & $32.26(2016)$ & $19.13(2$ & 03) & $26.53(2010)$ & 33.2 & 016) \\
\hline & & th Sud & & Suda & & & Uganda & & & anzania & \\
\hline & & & 2017 & 2012 & 2017 & 2007 & 2012 & 2017 & 2007 & 2012 & 2017 \\
\hline $\mathrm{SW}_{\mathrm{P}}$ & & & 26 & 2 & 2 & 39 & 39 & 39 & 80 & 80 & 80 \\
\hline $\mathrm{GW}_{\mathrm{R}}$ & & & 4 & 3 & 3 & 29 & 29 & 29 & 30 & 30 & 30 \\
\hline Q OUT-Q $_{\text {IN }}$ & & & 4 & 1 & 1 & 29 & 29 & 29 & 26 & 26 & 26 \\
\hline IRWR & & & 26 & 4 & 4 & 39 & 39 & 39 & 84 & 84 & 84 \\
\hline TRESW & & & 23.5 & 33.8 & 33.8 & 21.1 & 21.1 & 21.1 & 12.27 & 12.27 & 12.27 \\
\hline $\mathrm{GW}_{\mathrm{IN}}$ & & & 0 & 0 & 0 & 0 & 0 & 0 & 0 & 0 & 0 \\
\hline ERWR & & & 23.5 & 33.8 & 33.8 & 21.1 & 21.1 & 21.1 & 12.27 & 12.27 & 12.27 \\
\hline TRSW & & & 49.5 & 35.8 & 35.8 & 60.1 & 60.1 & 60.1 & 92.27 & 92.27 & 92.27 \\
\hline TRGW & & & 4 & 3 & 3 & 29 & 29 & 29 & 30 & 30 & 30 \\
\hline TRWR & & & 49.5 & 37.8 & 37.8 & 60.1 & 60.1 & 60.1 & 96.27 & 96.27 & 96.27 \\
\hline EFR & & & 33.93 & 15.1 & 15.1 & 49.17 & 49.17 & 49.17 & 56.28 & 56.28 & 56.28 \\
\hline FSWW & & & - & - & - & - & - & - & - & - & - \\
\hline FGWW & & & - & - & - & - & - & - & - & - & - \\
\hline TFWW & 0.65 & 011) & - & $26.93(2011)$ & - & - & $0.637(2008)$ & - & - & - & - \\
\hline WS & 4.22 & 011) & - & 118.6(2011) & - & - & $5.828(2008)$ & - & - & - & - \\
\hline
\end{tabular}

With the abbreviation list: $\mathrm{SW}_{\mathrm{P}}$-Surface water produced internally $\left(10^{9} \mathrm{~m}^{3} /\right.$ year), $\mathrm{GW}_{\mathrm{R}}$-Groundwater produced internally $\left(10^{9} \mathrm{~m}^{3} /\right.$ year $)$, Q OUT-Q internal renewable water resources $\left(10^{9} \mathrm{~m}^{3} /\right.$ year $)$, TRESW-Surface water: total external renewable $\left(10^{9} \mathrm{~m}^{3} /\right.$ year $)$, $\mathrm{GW}_{\text {IN }}$-Groundwater: entering the country (total) $\left(10^{9} \mathrm{~m}^{3} /\right.$ year), ERWR - Water resources: total external renewable $\left(10^{9} \mathrm{~m}^{3} /\right.$ year $)$, TRSW-Total renewable surface water $\left(10^{9} \mathrm{~m}^{3} /\right.$ year $)$, TRGW-Total renewable groundwater $\left(10^{9} \mathrm{~m}^{3} /\right.$ year), TRWR - Total renewable water resources $\left(10^{9} \mathrm{~m}^{3} /\right.$ year $)$, EFR-Environmental Flow Requirements $\left(10^{9} \mathrm{~m}^{3} /\right.$ year $)$, FSWW-Fresh surface water withdrawal $\left(10^{9} \mathrm{~m}^{3} /\right.$ year $)$, FGWW-Fresh groundwater withdrawal $\left(10^{9} \mathrm{~m}^{3} /\right.$ year), TFWW-Total freshwater withdrawal ( $10^{9} \mathrm{~m}^{3} /$ year $)$, WS-SDG 6.4.2. Water Stress (\%).

TRWR is calculated as being the sum of total internal and external renewable water resources, also equal to total renewable groundwater and surface water:

$$
\mathrm{TRWR}=\mathrm{IRWR}+\mathrm{ERWR}=\mathrm{TRSW}+\mathrm{TRGW}
$$

Total internal renewable water resources (IRWR) is calculated as the sum of internally produced surface water and groundwater with deducting their overlap:

$$
\mathrm{IRWR}=\mathrm{SW}_{\mathrm{P}}+\mathrm{GW}_{\mathrm{R}}-\left(\mathrm{Q}_{\mathrm{OUT}}-\mathrm{Q}_{\mathrm{IN}}\right)
$$

Total external renewable water resources (ERWR) is calculated as being the sum of external renewable surface water and groundwater:

$$
\mathrm{ERWR}=\mathrm{TRESW}+\mathrm{GW}_{\mathrm{IN}}
$$


TFWW is usually calculated as being: the sum of total water withdrawal with deducting the direct use of wastewater, direct use of agricultural drainage water and use of desalinated water. TFWW can be also calculated as the sum of total withdrawal of fresh surface water and groundwater:

$$
\mathrm{TFWW}=\mathrm{FSWW}+\mathrm{FGWW}
$$

From Table 2, some facts can be concluded regarding the current situation of monitoring Indicator 6.4.2 in the Nile Basin countries:

- Outdated and inconsistent data. The reference years $(2007,2012,2017)$ are a reported at a five years period and sometimes varied between variables and countries. For example, Sudan and South Sudan's data before 2012 is not available. Kenya's WS of 2007 is calculated by the 2003 TFWW data. This results in uncertainties between the actual and estimated water stress situation.

- Difference conditions of countries. Upstream countries (Ethiopia, Kenya, etc.) have IRWR as their major contributor of the TRWR, while downstream countries (Egypt and Sudan) heavily rely on ERWR (e.g., $56.5 \times 10^{9} \mathrm{~m}^{3} /$ year of ERWR out of total $57.5 \times 10^{9} \mathrm{~m}^{3} /$ year of TRWR for Egypt).

- Groundwater usage and recharge. All the countries, except Egypt, have their groundwater recharge internally. Egypt has total renewable groundwater (TRGW) of $1.5 \times 10^{9} \mathrm{~m}^{3} /$ year yet with higher FGWW of 7.5 and $6.5 \times 10^{9} \mathrm{~m}^{3} /$ year for the year 2012 and 2017, respectively. The decreased FGWW contributes to a lower TFWW that mitigates the water stress value from $124 \%$ to $117.3 \%$.

- $\quad$ Overgeneralized spatial and temporal data. The country level data at a five year period overlooks the distribution of the water stress within the country and may hide specific situations that only exist for part of the year.

Therefore, the current data-collection process of Indicator 6.4.2 is not comprehensive and can be assisted by the EO data. In this study, the EO hydrological data is used to show the spatial distribution of water resources among the Nile Basin countries in a higher temporal scale. The tasks are performed to: (1) show the changing trend of water resources related to water stress situations (e.g., precipitation, evapotranspiration, groundwater, etc.); (2) present the connection between groundwater and hydrological parameters related to surface water; (3) compare the groundwater withdrawal and renewable groundwater from natural resources; and (4) explore the spatial and temporal recharge patterns of groundwater from internal and external resources. The hydrological datasets is introduce in the Section 2.2.1.

\subsubsection{Hydrological Datasets}

- NASA-United States Department of Agriculture (USDA) Global Soil Moisture Dataset

The NASA-USDA Global soil moisture dataset [27-30] includes information of surface and subsurface soil moisture, soil moisture profile (\%), as well as surface and subsurface soil moisture anomalies represented as unitless and standardized values (negative/positive either refers to drier/wetter than normal conditions, respectively) computed using a 31-days moving window. The dataset has spatial resolution of $0.25^{\circ} \times 0.25^{\circ}$ at global scale and temporal resolution of 3 days starting from 1 January 2010. This dataset is generated through the data assimilation approach, which employs a modified two-layer Palmer model using a 1-D ensemble Kalman filter (EnKF) to integrate the satellite-derived Soil Moisture Active Passive (SMAP) Level 3 soil moisture observations. This approach turns out to be helpful to improve the model-based soil moisture predictions, particularly for the Nile watershed region, which lacks good quality hydrological measurements. The unit of soil moisture is in $\mathrm{mm}$.

- Climate Hazards Group Infrared Precipitation with Station Dataset

The precipitation dataset is obtained from the Climate Hazards Group Infrared Precipitation with Station (CHIRPS) dataset (version 2.0) [31]. CHIRPS is a 30+ year quasi-global rainfall dataset, which is developed by the United States Geological Survey (USGS) in collaboration with the Earth Resource 
Observation and Science Center (https://www.usgs.gov/centers/eros). The dataset incorporates $0.05^{\circ}$ resolution satellite imagery with in situ station data with temporal resolution as pentad (i.e., the first 5 pentads in a month have 5 days and the last pentad contains all the days from the 26th to the end of the month) to create gridded precipitation time series for trend/correlational analysis and drought/flood monitoring.

- Famine Early Warning Systems Network (FEWS NET) Land Data Assimilation System (FLDAS) Dataset

The evapotranspiration (ET) and runoff data is obtained from the FEWS NET FLDAS [32,33]. The FLDAS is designed particularly to assist the food security investigations for the developing countries with sparse data accessibility. In this research, the version of FLDAS dataset used in this study is the Noah version 3.6.1 surface model with downscaled CHIRPS-6 hourly precipitation inputs using the NASA Land Surface Data Toolkit (https://lis.gsfc.nasa.gov/software/ldt). The model uses a combination of the new version of Modern-Era Retrospective analysis for Research and Applications version 2 (MERRA-2) data and CHIRPS as the forcing data. The dataset provides monthly average value with spatial resolution of 0.1 arc degrees. Besides, the total runoff is computed from the sum of surface storm runoff (Qs_tavg) and baseflow-groundwater runoff (Qsb_tavg). The unit of the FLDAS data is translated from $\mathrm{kg} \mathrm{m}^{-2} \mathrm{~s}^{-1}$ to $\mathrm{mm} \mathrm{s}^{-1}\left(1 \mathrm{~kg} \mathrm{~m}^{-2}=1 \mathrm{~mm} \mathrm{H}_{2} \mathrm{O}\right)$.

- Gravity Recovery and Climate Experiment (GRACE) Mission Monthly Gravitational Anomalies

GRACE Tellus Monthly Mass Grids [34-36] provides monthly gravitational anomalies relative to a 2004-2010 time-mean baseline. The dataset uses the units of "equivalent liquid water thickness" (LWE) which represent the deviations of mass in terms of vertical extent of water in centimeters. The GRACE mission operated from April, 2002 to June, 2017. The GRACE satellites measure the spatial and temporal variability in the Earth's gravity field and the monthly gridded terrestrial water storage (TWS) products are available from the NASA Jet Propulsion Laboratory (JPL) Tellus website (https:/grace.jpl.nasa.gov/data/get-data/monthly-mass-grids-land/) on 1 horizontal resolution grids and global coverage. The unit of the GRACE data is also translated from centimeters to $\mathrm{mm}$.

\subsubsection{Multi-Assessment Methodologies of Water Stress Addressing SDG 6}

Harmonic analysis is a method involving the representation of functions or signals as a superposition of elementary waves. In this study, to estimate the variation of multiple hydrological factors (e.g., precipitation), we build the harmonic model $H(t)$ with elements of a constant band $\left(\beta_{0}\right)$, a linear term of slope $\left(\beta_{1}\right)$ and harmonic terms of amplitudes $\left(\beta_{2}, \beta_{3}, \beta_{4}\right.$ and $\left.\beta_{5}\right)$. The term $\beta_{1}$, associated with the linear part of the factor, represents the increasing/decreasing trend, whereas a constant band $\beta_{0}$ represents the extent of consistency of the time series. Moreover, $f$ represents the fundamental frequency. The $\beta_{1}$ of the harmonic analysis can show linear trend of a series regardless of the seasonal variations. The $t$ is the record for each parameter including monthly LWE, total monthly precipitation, total monthly water lost from evapotranspiration and runoff, as well as averaged monthly surface soil moisture. All the data used are accessed from the Google Earth Engine platform through sampling of random points (200 to 300 points according to the country size) within the overlapped region of both Nile watershed and countries' territories. For example, the sample points used in the Egypt region are presented in Figure 1. In this research, the value $\beta_{1}$ shows the monthly trend in the Nile watershed regardless seasonal variations.. Positive value presents increasing trend, and negative value decreasing.

$$
H(t)=\beta_{0}+\beta_{1} t+\beta_{2} \cos (2 \pi f t)+\beta_{3} \sin (2 \pi f t)+\beta_{4} \cos (4 \pi f t)+\beta_{5} \sin (4 \pi f t)
$$

The precipitation, ET, surface soil moisture, runoff and LWE products are used to generate the changing trend map of the Nile watershed region during May 1st, 2013 till October 20th, 2019 using month values: (1) precipitation: total precipitations (in millimeters) within a month; (2) ET and runoff: the monthly averaged value (in $\mathrm{mm} \mathrm{s}^{-1}$ ) multiplies by the total seconds of 30 days (2,592,000 seconds); 
(3) soil moisture: the monthly averaged value (in millimeters); and (4) LWE groundwater: the monthly records (in millimeters). In addition, the relationship between the parameters and groundwater recharge pattern is studied by the lag correlation analysis using their anomalies value $X_{a}$ calculated as Equation (7).

$$
X_{a}=X-\bar{X}
$$

with $X$ as the monthly value and $\bar{X}$ as the monthly mean value.

In the previous comparative global study of water availability in the major river basins [37], the basin averaged water balance was estimated through Equation (8) and compared to the GRACE water LWE anomaly through Equation (9).

$$
\begin{gathered}
P-E T-R=\Delta S \\
\Delta S=\Delta S_{\mathrm{GRACE}}+\Delta S_{\text {human }}
\end{gathered}
$$

where precipitation $(\mathrm{P}), \mathrm{ET}$, runoff $(\mathrm{R})$, and change in surface and subsurface water storage $\Delta S$ are monthly and basin-averaged values for each of the basins. The left-hand variables of Equation (9) can be estimated from the satellite observations or model outputs, while the right-hand $\Delta S$ is estimated thought the GRACE observations $\left(\triangle S_{\mathrm{GRACE}}\right)$, as well as other factors related to human activities $\left(\Delta S_{\text {human }}\right)$, such as of exploitation of groundwater in the basin for agricultural or industrial purposes.

\subsection{Data and Methods to Study SDG 11 Indicator on Urbanization Process}

Target 11.3 of SDG 11 is to "enhance inclusive and sustainable urbanization and capacity for participatory, integrated and sustainable human settlement planning and management in all countries." Its Indicator 11.3.1, "Ratio of land consumption rate to population growth rate" (LCRPGR) shown in Equation (10), is defined as the ratio of land consumption rate (LCR) to population growth rate (PGR) and is used to describe the urbanization process and population growth.

$$
L C R P G R=\frac{\text { land consumption rate }}{\text { annual population growth rate }}=\frac{L C R}{P G R}
$$

In particular, it is discovered that urban impervious surfaces retrieved from the remote-sensing imagery can effectively reflect urban surface and land use information [10]. Some countries (e.g., US [38], China [39]) have developed regional high-resolution urban land mapping datasets. However, many developing countries do not have the technical and financial resources to monitor their urban development. Therefore, the goal of this study is to develop a transfer learning method using freely assessable EO and land cover datasets, as well as computing resources to monitor the impervious surface changes of urban cities in the Nile Basin countries. This study will enable the developing countries to investigate the relationship between land use and population growth rate in urban environment. In addition, we also evaluate the effectiveness of this method to target slums urbanization situation, in order to monitor Indicator 11.1.1 "proportion of urban population living in slums, informal settlements or inadequate housing".

\subsubsection{Land-Cover Datasets}

\section{- USGS Landsat 8 Surface Reflectance}

The Landsat 8 Surface Reflectance Tier 1 dataset [40] observed from Operational Land Imager (OLI) and Thermal Infrared Sensor (TIRS) is used in this research. The imagery has been atmospherically corrected by the Landsat Ecosystem Disturbance Adaptive Processing System (LEDAPS). It includes the per-pixel saturation mask and cloud, shadow, water and snow masks from C Function of Mask (CFMASK). The data has been available since 11 April 2013 and generated by Google using a Docker image supplied by USGS. The images contain 5 visible and near-infrared (VNIR) bands of $30 \mathrm{~m}$ 
resolution, 2 short-wave infrared (SWIR) bands of $30 \mathrm{~m}$ resolution processed to orthorectified surface reflectance, and two thermal infrared (TIR) band of resampled $30 \mathrm{~m}$ resolution for processing to orthorectified brightness temperature. In this study, we utilized Landsat 8 imagery composites of the period from 1 May to 20 October 2013 and 1 May to 20 October 2019 for the five capital cities in order to compare the changes of the percentage of impervious surfaces. The imagery composites are generated through rigorous cloud masking and quality assurance, as well as transformation of the temperature unit from Kelvin to Celsius.

- The National Land Cover Database (NLCD)

NLCD [38] is a land-cover database based on $30 \mathrm{~m}$ Landsat images. It includes 8 epochs (1992, 2001, 2004, 2006, 2008, 2011, 2013 and 2016), in which the 1992 data are not directly comparable to the later epochs since it is generated from unsupervised classification method while other editions are based on the imperviousness data layer for the urban classes and on a decision-tree classification for the rest classes. The dataset is generated by the Multi-Resolution Land Characteristics (MRLC) Consortium, a partnership of federal agencies led by the US Geological Survey. However, the dataset only covers the regions of continental US for each of the eight epochs, plus separate images for Alaska, Hawaii, and Puerto Rico in 2001 and 2011. In this study, the training model is built with inputs from the NLCD parameter (NLCD2016) representing the percent of the pixel covered by developed impervious surface of the year 2016.

\subsubsection{Modeling of Impervious Surfaces Addressing SDG 11}

The modeling approach in this study is built on the infrastructure provided by Google's full-stack geospatial modeling and analysis platform: (1) Google Earth Engine as the geospatial analysis platform; (2) Earth Engine Data Catalog as the geospatial data archive that can be accessed and analyzed in the cloud computing platform; (3) TensorFlow as the machine learning platform to implement model design; (4) artificial intelligence (AI) Platform as to build and run the models and (5) Colab as the Jupyter notebook server for the workflow development. Firstly, the Earth Engine requests the training data from the Earth Engine Data Catalog stored in the cloud storage. Secondly, the cloud storage finds the training data and sends it to the AI Platform, while the AI Platform receives the model designed by the TensorFlow and its application programming interfaces (APIs) programmed in the Colab server. When the model is built completely, GEE can access the model to make predictions through its new functionality API of ee.Model.fromAIPlatformPredictor and output the results. This update of GEE's API to have new integration with Google Cloud's AI Platform expands its modeling scalability and enhances its analytical capabilities. The traditional APIs in the GEE include the machine-learning algorithms such as decision trees, K-means and support vector machine. However, these methods have limited capability to extract information from high-dimensional (number of bands $>>3$ ) imagery about not just the spectral values from one pixel, but spatial patterns of many pixels (i.e., the spatial context) represented as big patches of pixels (e.g., $256 \times 256$ ). Therefore, the fully convolutional neural networks (FCNNs) [41] are designed to handle these difficulties. FCNN contains one or more convolutional layers, in which inputs are neighborhoods of pixels. Therefore, it learns from patches of data, instead of single pixels, resulting in a network that is not fully connected, but is suited to identifying spatial patterns. In this study, the FCNN model is trained from training data from NLCD dataset and predicts a continuous range from 0 to 1 output in each pixel from $256 \times 256$ neighborhoods of pixels to show the percentage of the impervious surface levels. The example provided in the Colab document (https://colab.research.google.com/github/google/earthengine-api/blob/master/ python/examples/ipyn-b/UNET_regression_demo.ipynb) shows the details of how to export patches of data to train the network and how to overtile image patches for inference, to eliminate tile boundary artifacts. The Landsat 8 surface reflectance data has been rescaled to range from 0 to 1 for both seven reflectance bands and the two thermal temperature bands were between $0{ }^{\circ} \mathrm{C}$ to $100{ }^{\circ} \mathrm{C}$. Therefore, the processed Landsat 8 composite image in 2016 is ready to be trained with the NLCD impervious 
surface as an objective field. The training patches are obtained from cities across the continental US shown in Figure 2a (red as training regions and blue as evaluation regions). Total 20,000 and 8000 patches are used for training and evaluation, respectively, including a total 50 epochs (one epoch is a full processing by the learning algorithm over the entire training set). The model uses the Stochastic gradient descent (SGD) and momentum method as the optimizer, the mean of squares of errors as the loss function, and the root mean squared error as the metrics. The model is optimized by minimizing the loss and monitoring the metrics values at the end of each epoch. The modelling process took 1 day 6 hour and 57 mins, and the process is displayed in the Figure $2 \mathrm{~b}$.

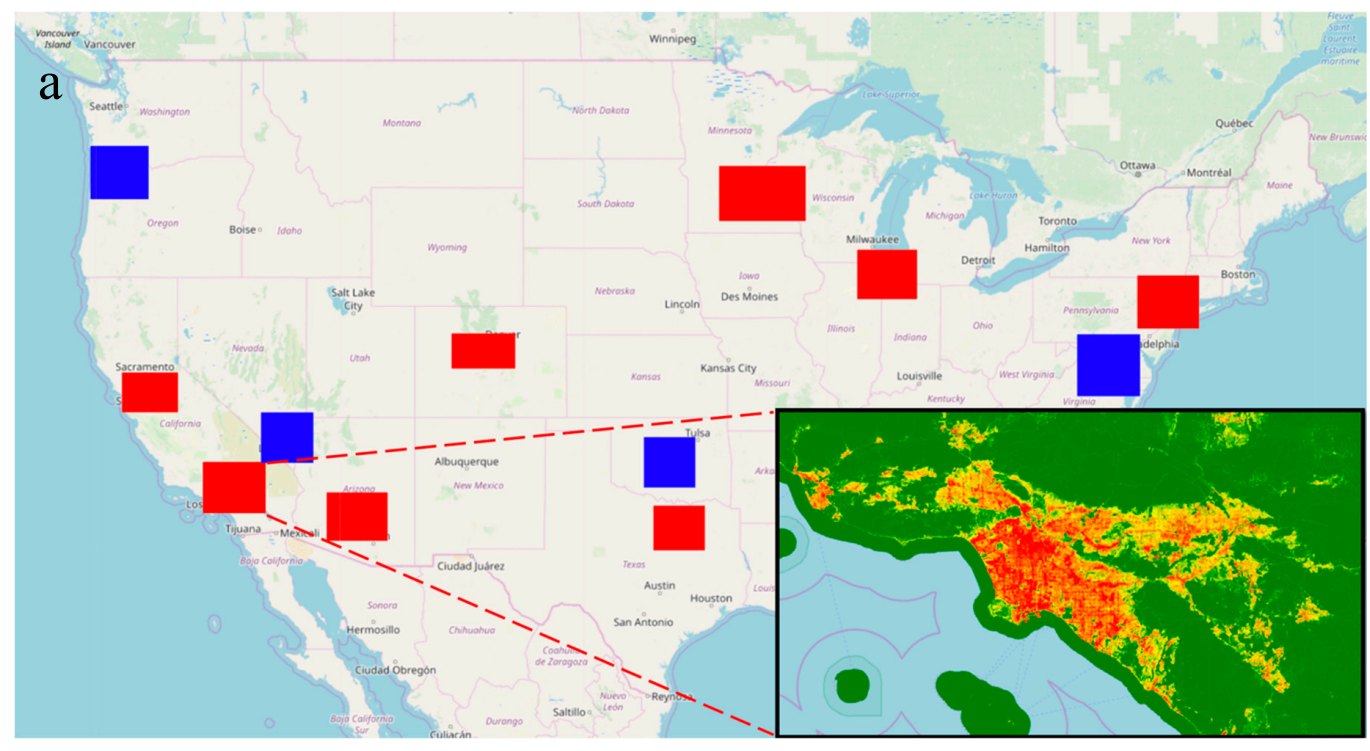

epoch_loss

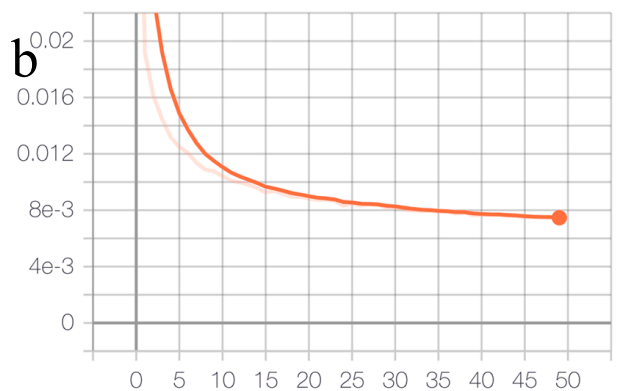

epoch_val_loss

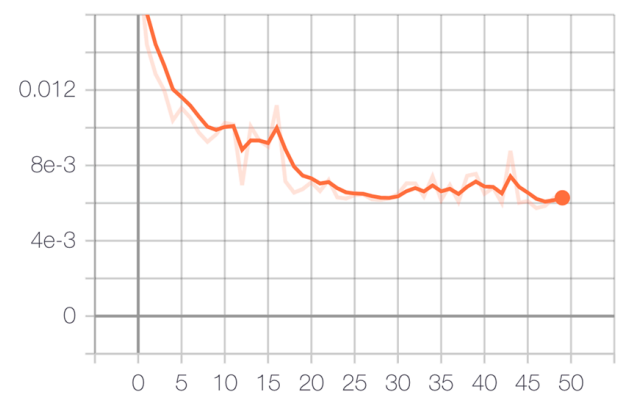

epoch_root_mean_squared_error

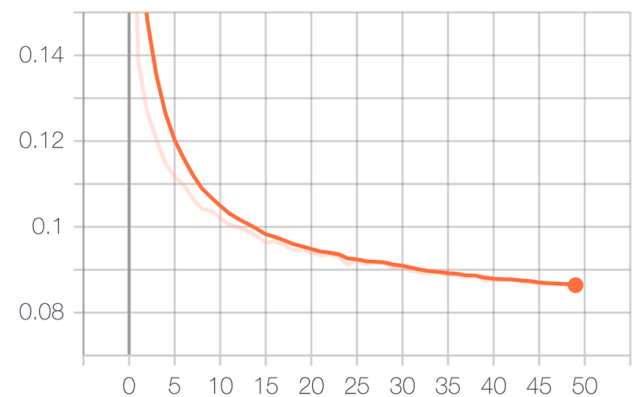

epoch_val_root_mean_squared_error

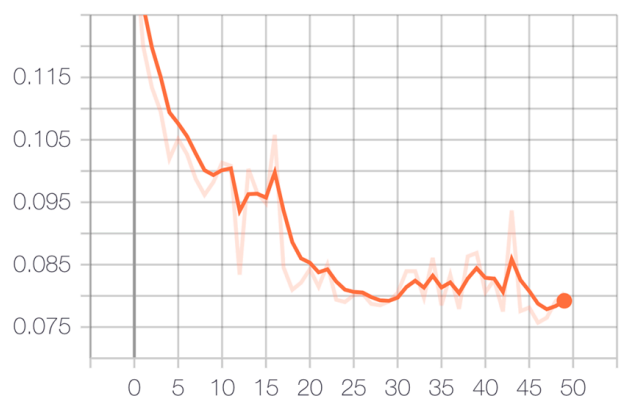

Figure 2. (a) Locations of the sampling polygons on the United States map, red for training polygons, blue for evaluation. The map on the right bottom shows the impervious surface percentage (red as $100 \%$ and green as $0 \%$ ) region of the Metropolitan Los Angeles; (b) the charts of the modeling process regards of loss function and root mean squared error for the training (upper) and evaluation (lower) datasets. The lighter lines show the calculated values from the loss function and the darker lines show the smoothed values (y-axis) for each epoch (x-axis). 


\section{Results}

\subsection{Comparision of Changing Trends among Multiple Hydrological Parameters}

Figure 3 illustrates the changing trends of multiple hydrological factors (precipitation, ET, surface soil moisture, runoff and LWE) over the Nile watershed calculated based on harmonic analysis during the period between the years 2002-2017, (2010-2017 for surface soil moisture due to data availability), with p-values indicting the validity of trend except limited regions in Egypt and Sudan for the surface soil moisture and runoff, respectively. It is observed that the changing trends of precipitation and ET (e.g., location A), as well as the precipitation and runoff in Ethiopia (e.g., location B), are very similar. This may be due to FLDAS having CHIRPS rainfall as model input. The trends show an increase in the Sudan, South Sudan and most regions in Uganda and Tanzania. Noted decreasing change is also calculated in the Sudan and South Sudan and Ethiopia region. Surface soil moisture has increased for most of the watershed except some regions in South Sudan and Uganda. The Nile Delta region has an increase of surface soil moisture in much of the basin which corresponds to an increase in precipitation. Increasing LWE is found in Sudan, Ethiopia, Uganda, Kenya and Tanzania but not South Sudan. The runoff values stay the same for most of the watershed yet have an increasing trend in the limited regions of South Sudan, Ethiopia, Kenya and Uganda, while having some overlapping regions with decreased surface soil moisture.
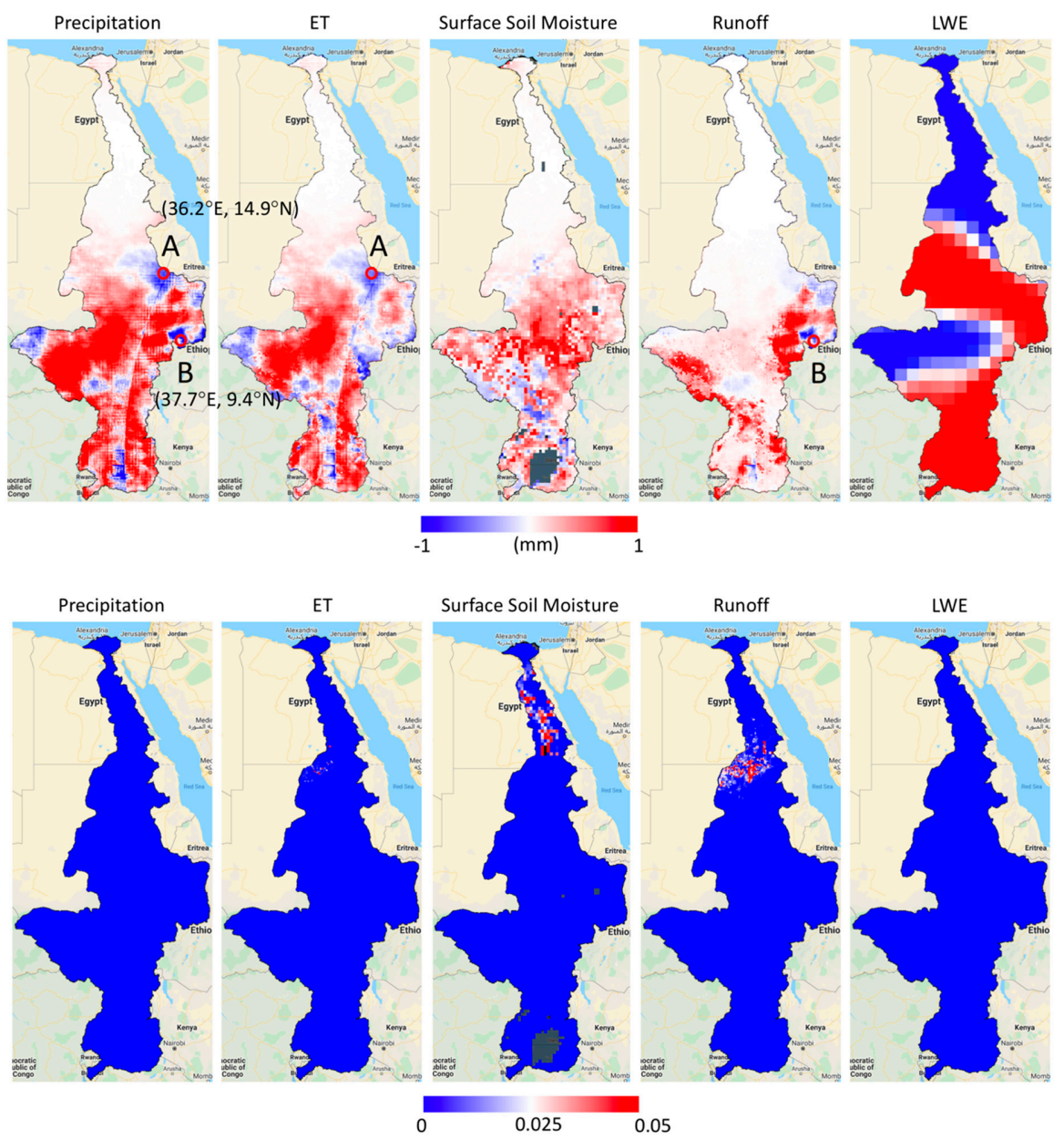

Figure 3. Changing trends of multiple hydrological factors (precipitation, evapotranspiration (ET), surface soil moisture, runoff and equivalent liquid water thickness (LWE)) over the Nile watershed calculated based on harmonic analysis of the periods between the years 2002-2017 (first row), as well as the degree of significance test using p-value (second row) (Note: surface soil moisture trend is calculated using the averaged value of the period 2010-2017 due to data availability). 


\subsection{The Relationship between the Groundwater Variablity and Multiple Hydrological Parameters}

Figure 4 shows positive correlations between multiple parameters (surface soil moisture, ET, runoff and precipitation) and LWE. However, such relationship is not plausible for the low p-value for most of the region, except: (1) positive relationship between surface soil moisture and LWE in South Sudan and Uganda (region A); (2) positive relationship between ET and LWE in Uganda and Kenya (region B) but negative in boundary parts in Ethiopia and Sudan (region C); (3) positive relationship between runoff and LWE in areas of Sudan (region D), Ethiopia (region E), South Sudan and Uganda (region F); and (4) positive relationship precipitation and LWE in areas of Sudan and Egypt (region G).
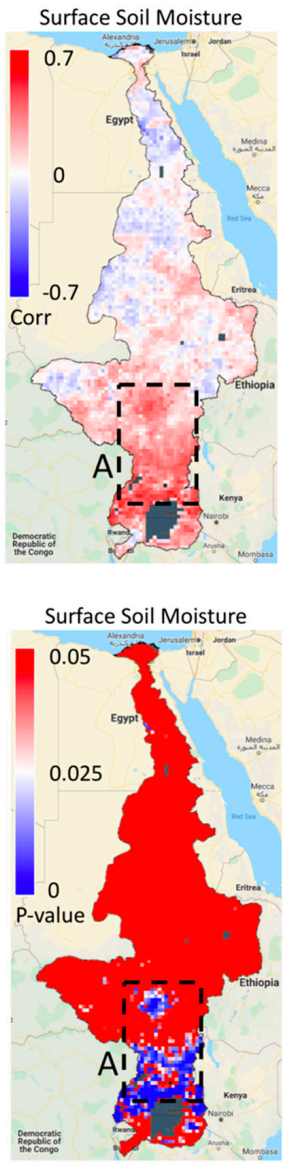
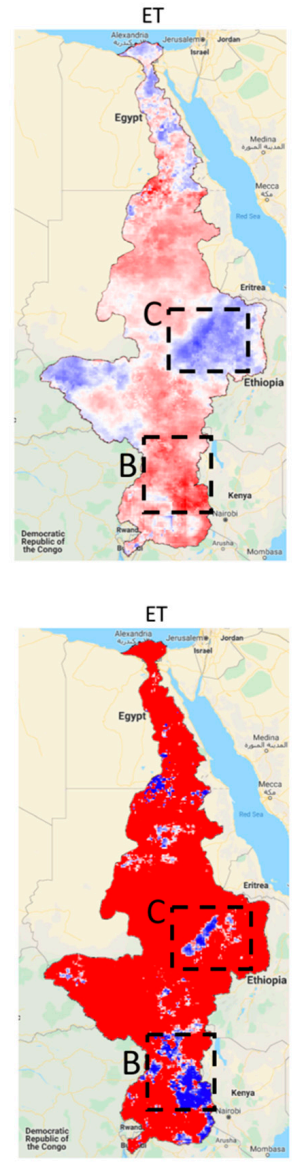
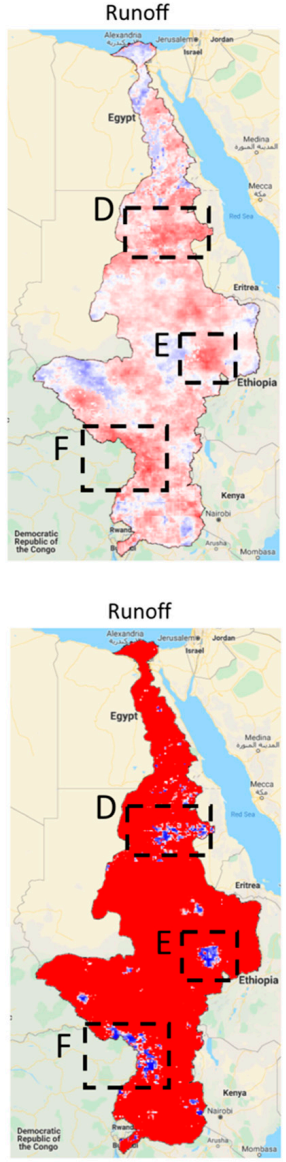
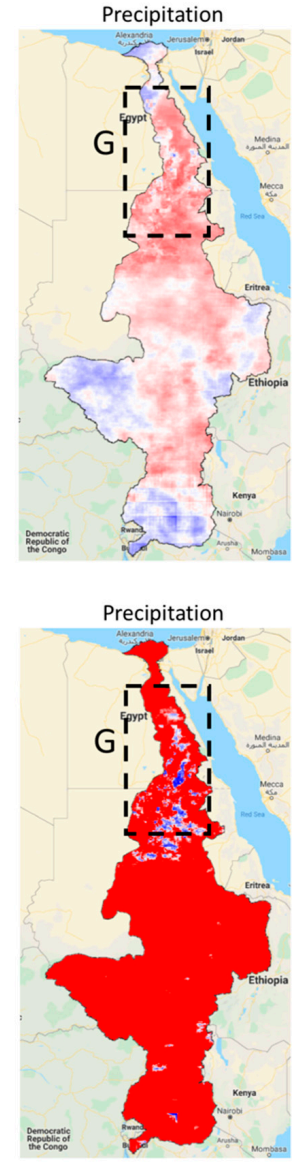

Figure 4. The correlation maps (correlation coefficient) between monthly anomalies values of LWE and other hydrological factors (precipitation, ET, surface soil moisture, runoff) over the Nile watershed (first row); and their p-value maps (second row). The values are calculated based on Pearson correlation analysis of the periods between the years 2002-2017 (2010-2017 for surface soil moisture). The regions $\mathrm{A}-\mathrm{G}$ are the areas with low $(<0.05) \mathrm{p}$-values.

In Figure 5, the time series analysis of the sampled locations is used to compare LWE and P-ET-R (precipitation minus ET and runoff) over the Nile watershed and the included countries (Egypt, Ethiopia, Kenya, South Sudan, Sudan, Tanzania and Uganda) during the period from 2002 till 2017.

The Nile watershed exhibits seasonal variations of P-ET-R and LWE during the years, with the lowest LWE after 2011 but the highest during the fall of 2014, showing a trend of increase since 2011. Egypt shows low variability of P-ET-R for its limited precipitation, ET and runoff sampled in the relatively small area (the Nile valley). Besides, the LWE level stays below zero during from early 2010 to the end of 2015, which indicates continuous groundwater loss during the period. The situation is significant for the year 2012. Ethiopia shows a strong lag correlation between P-ET-R and LWE. The peaks of P-ET-R occur several months ahead of peaks of LWE. This lag relationship can also be 
seen in South Sudan and Sudan. The LWE variability of Ethiopia is higher than Sudan but lower than South Sudan. For Kenya, Uganda and Tanzania, the seasonal variations of LWE and P-ET-R are not as strong as those shown in Ethiopia, South Sudan and Sudan. LWE in the three countries demonstrates a decreasing trend during 2003-2006 and an increasing trend during 2011-2016. Additionally, the P-ET-R shows a general pattern of double peaks during spring and fall annually.

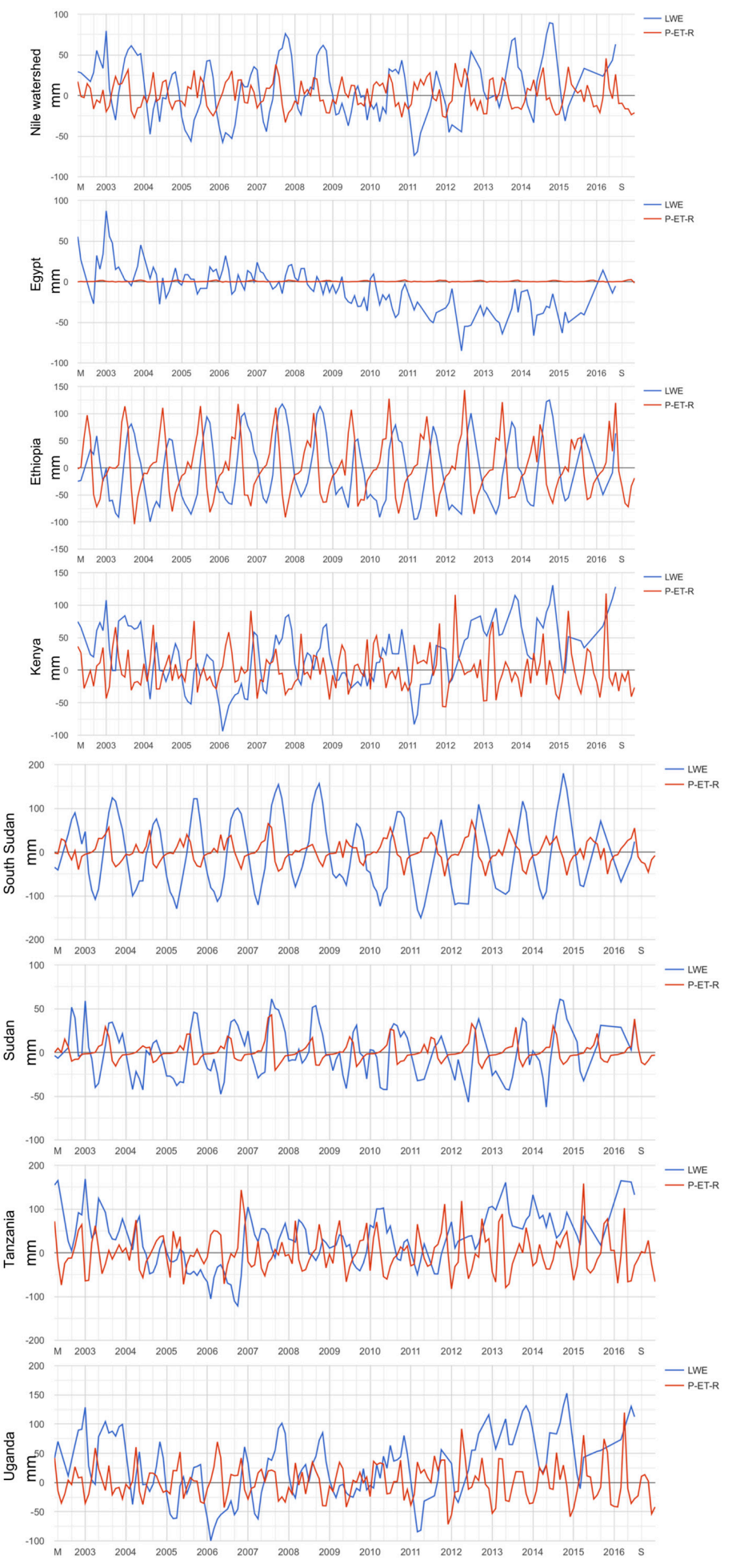

Figure 5. The time series line charts to compare LWE and P-ET-R (precipitation minus ET and runoff) over the Nile watershed and the countries (Egypt, Ethiopia, Kenya, South Sudan, Sudan, Tanzania and Uganda) during the period between 2002 and 2017. 
Figure 6 shows the correlation maps of correlation coefficient (Corr) and p-value between P-ET-R and LWE up to 3 months lags apart. The Corr value for the regions with p-value higher than 0.05 (red color) is not considered plausible. In the case of lag $=0$, the positive relationship is found near the south of Egypt. South Sudan, some parts of Ethiopia and Uganda demonstrate a negative relationship, which may be due to the coincidence between high LWE and low precipitation seasons. In the case of lag $=1$, only some regions of Egypt, Sudan and Ethiopia show a weaker positive relationship between P-ET-R and LWE. However, for lags of 2-3 months, the strong positive connections between P-ET-R and LWE are illustrated in the most of the regions in South Sudan, Ethiopia and southern part of Sudan, indicating the recharge process to the groundwater. This result also matches the observed relationship between the peaks of P-ET-R and LWE in Sudan, South Sudan and Ethiopia in Figure 5.
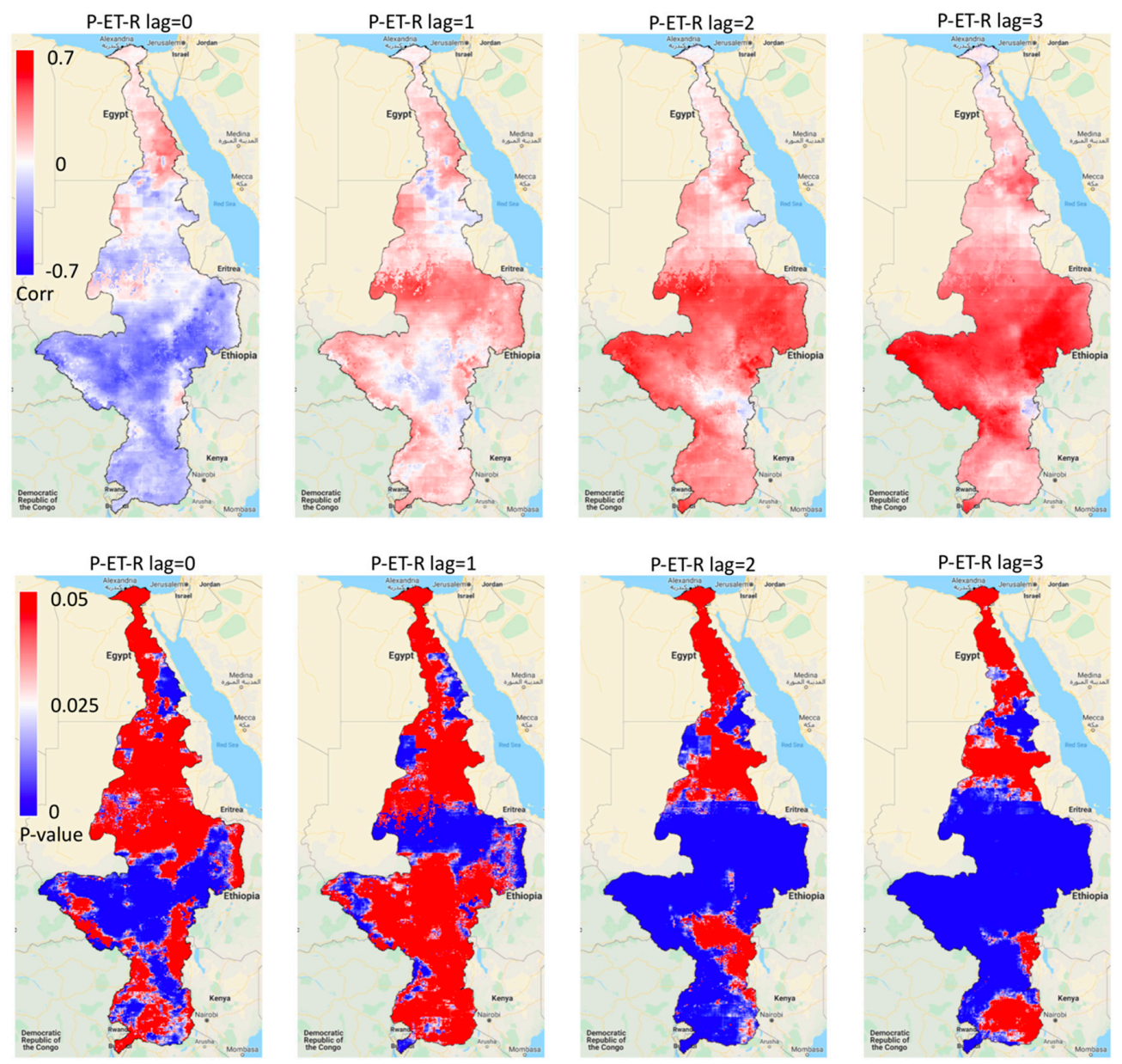

Figure 6. The correlation maps (correlation coefficient and p-value, up to 3 months of lags apart) between LWE and P-ET-R (precipitation minus ET and runoff) over the Nile watershed calculated based on Pearson correlation analysis of the periods between the years 2002-2017.

\subsection{The Change Detection of Impervious Surface among Multiple Selected Cities between 2013 and 2019}

Figure 7 shows the Landsat- 8 true color composite images and corresponding impervious surface maps classified by the FCNN model. To compare the changes between the year 2013 and 2019 among five capital cities in the Nile watershed, Table 3 shows the ratio of highly impervious surface (value $>50 \%$ ) areas for the years of 2013 and 2019 and the changes $\Delta$. Three cites (Khartoum, Addis Ababa and Kampala) illustrate an expansion in the percentage of impervious surface to some extent, with additional red or yellow colored regions. For Cairo, the ratio unexpectedly decreased since the additional impervious surface areas are seen at the eastern region at the New Cairo City. This may be due to the classifier, which cannot identify some regions of human habitats as it is observed that massive 
regions of human habitats are not marked as impervious surface (red arrows). Similarly, the community of the western outskirt of Khartoum (red rectangle) is also missed. For Juda, the decreased ratio may result from the dramatic changes of the settlements and constructions in the context of the South Sudanese Civil War since December 2013.
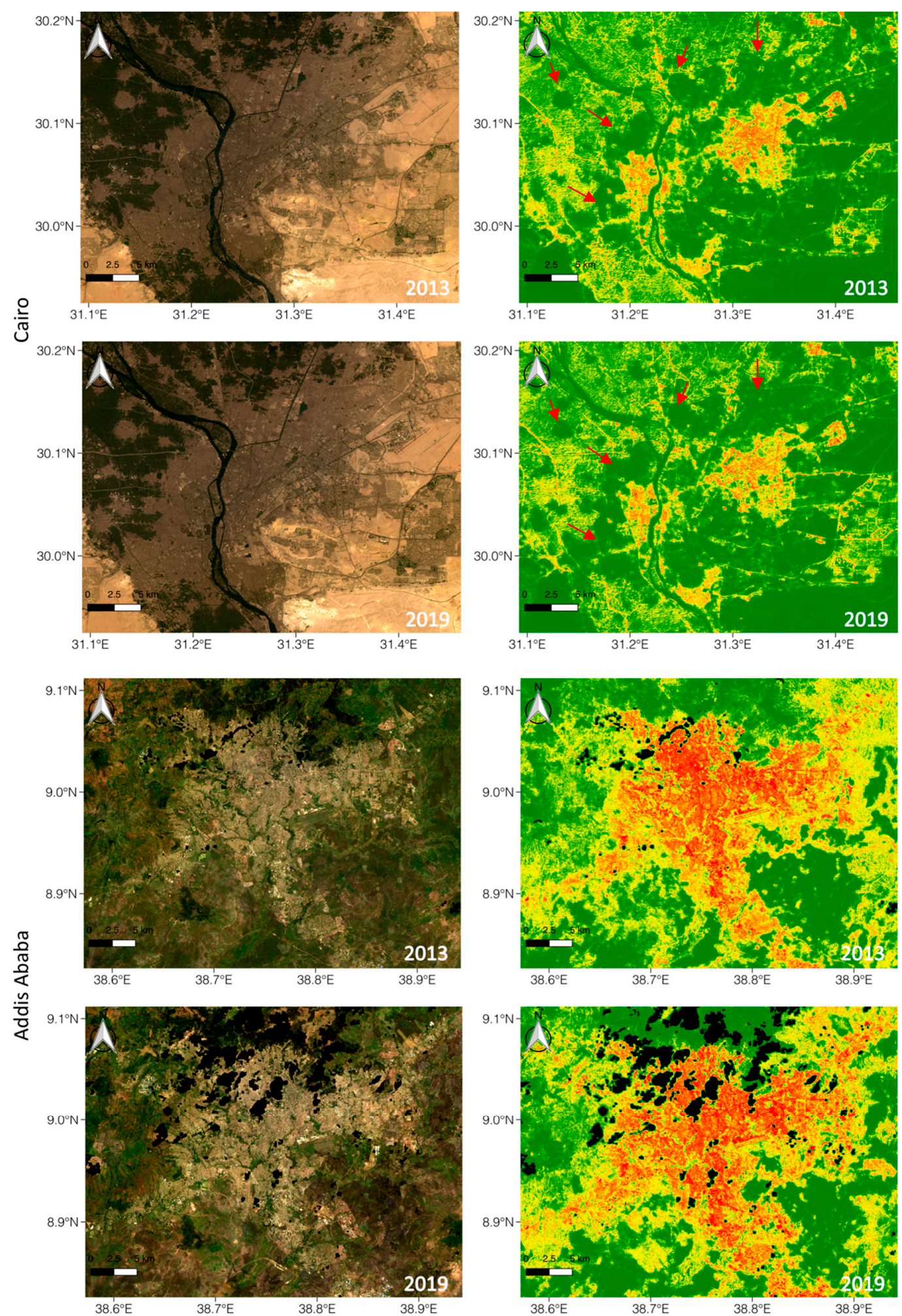

Figure 7. Cont. 

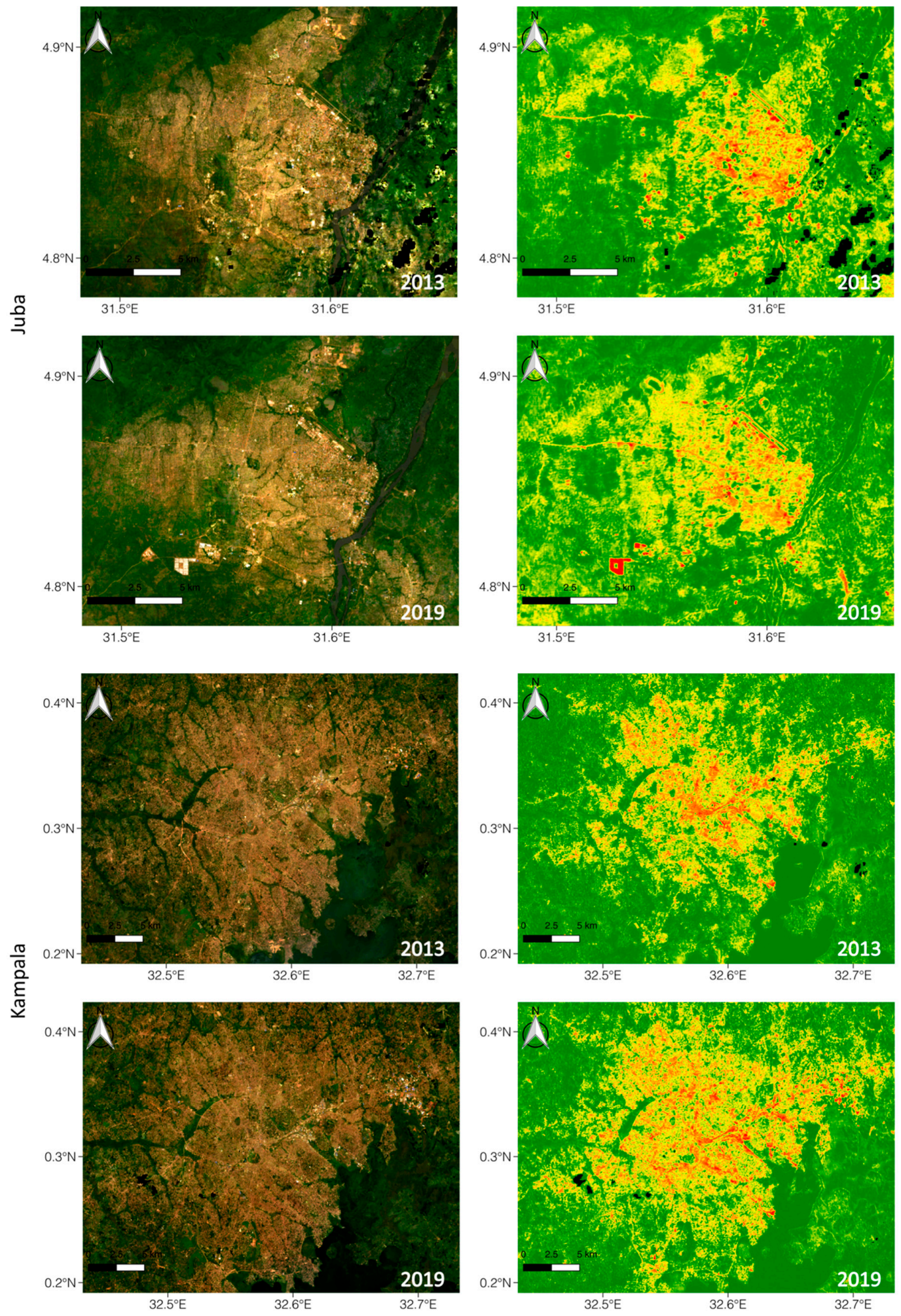

Figure 7. Cont. 


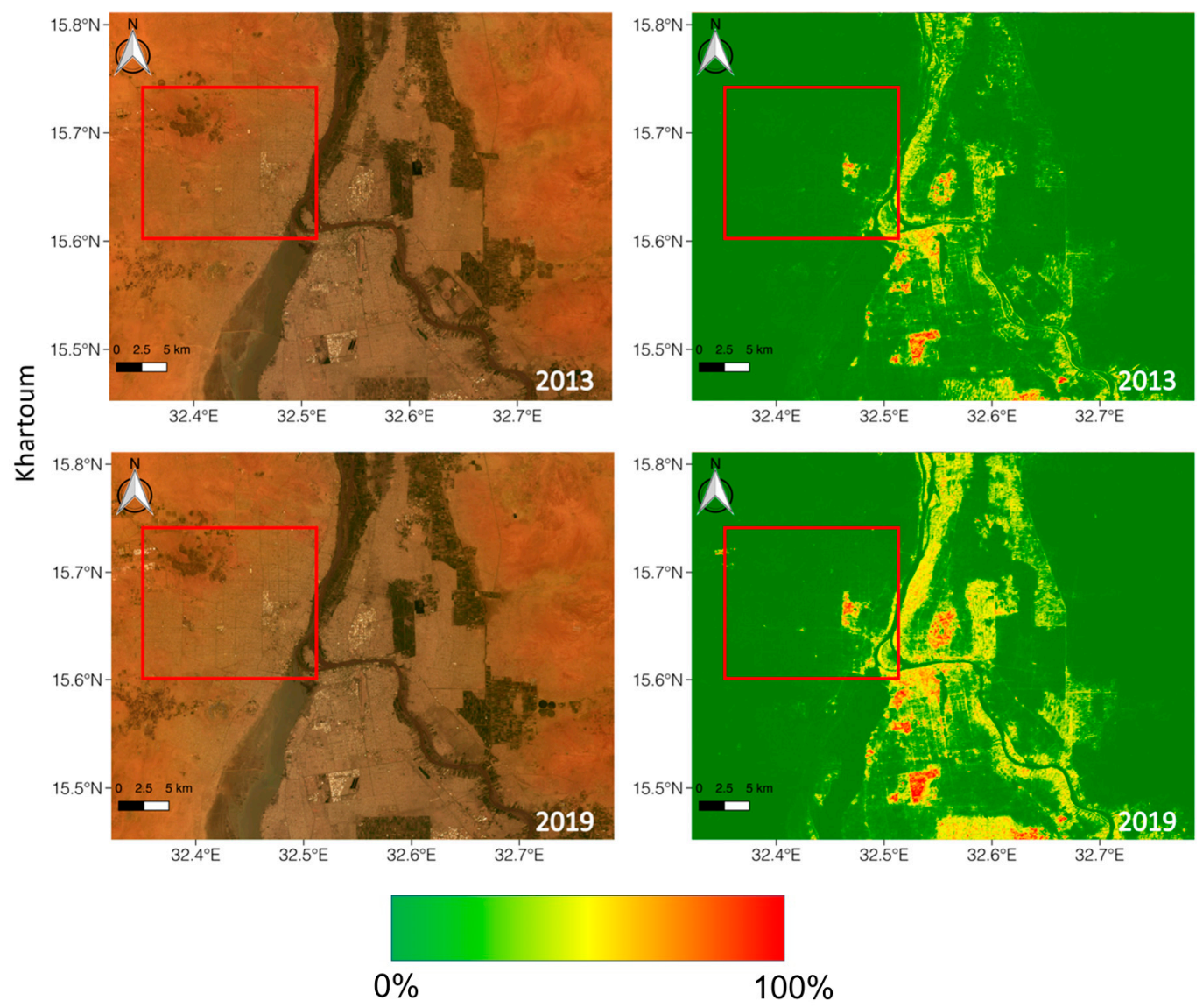

Figure 7. The Landsat- 8 true color composite images and corresponding impervious surface (red as 100\% and green as 0\%) maps in the year 2013 and 2019, for the selected cities including Cairo, Addis Ababa, Juba, Kampala and Khartoum.

Table 3. The changes of impervious surface areas (value $>50 \%$ ) in selected cities.

\begin{tabular}{cccc}
\hline City & $\mathbf{2 0 1 3}$ & $\mathbf{2 0 1 9}$ & $\boldsymbol{\Delta}$ \\
\hline Cairo & $14.4 \%$ & $12.3 \%$ & $-2.1 \%$ \\
Khartoum & $10.6 \%$ & $23.7 \%$ & $13.1 \%$ \\
Juda & $12.2 \%$ & $11.4 \%$ & $-0.8 \%$ \\
Addis Ababa & $39.1 \%$ & $44.5 \%$ & $5.4 \%$ \\
Kampala & $14.9 \%$ & $25.4 \%$ & $10.5 \%$ \\
\hline
\end{tabular}

To further explore the cause of misclassification of the impervious surface in the Cairo region, Figure 8 is created to show the surface reflectance signatures of the samples (selected locations shown on the left of Figure 8) in four types of land categories, namely, human habitats not marked as high impervious surface (Unmarked Habitat), human habitats marked as high impervious surface (Marked Habitat), barren areas (Barren) and vegetation areas such as croplands or grasslands (Vegetation). The barren surface shows a highest surface reflectance over B2-B7, while vegetation surface has high B5 (Near Infrared) in contrast to B4 (Red). However, the unmarked and marked habitats only have slight differences of surface reflectance values in the bands B6 (Shortwave Infrared 1) and B7 (Shortwave Infrared 2). Meanwhile, the values of marked habitats have wider confidence intervals than the unmarked in each band. 

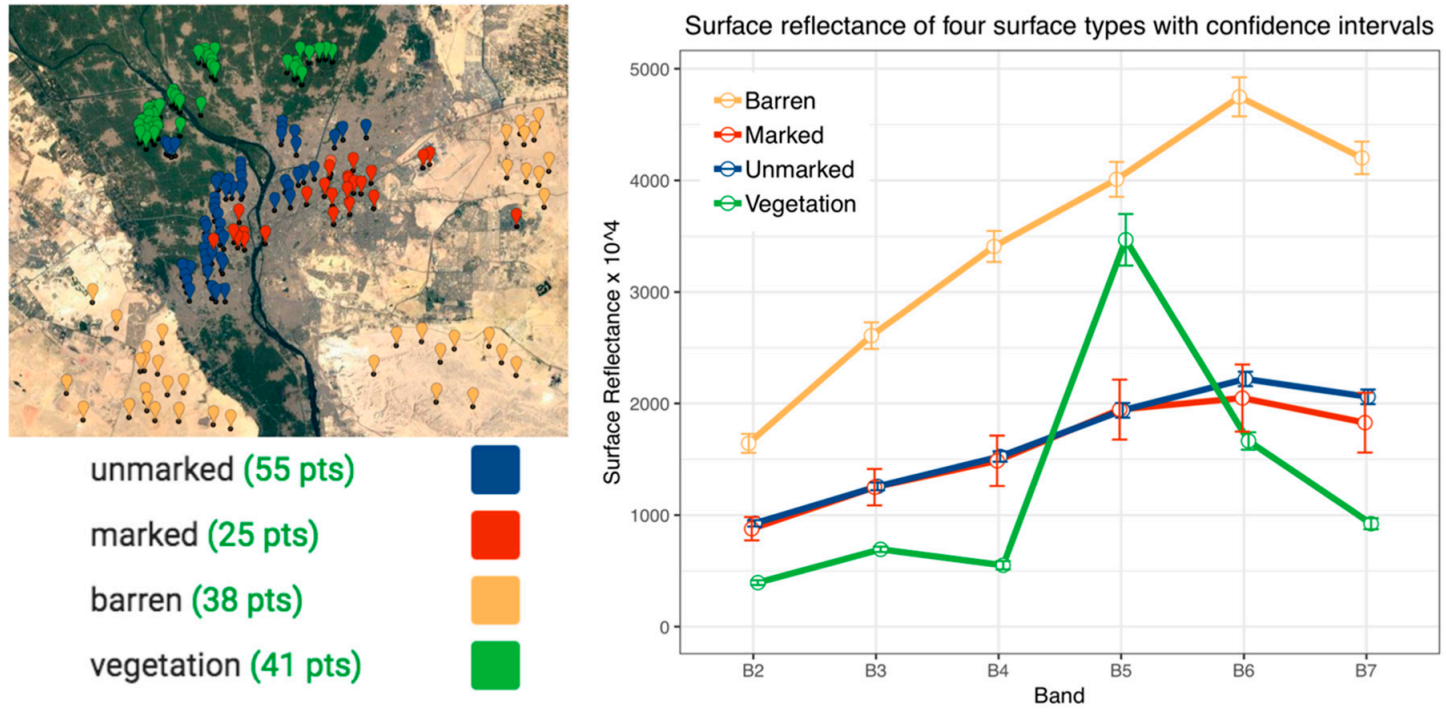

Figure 8. The surface reflectance for four types of land-cover surfaces with confidence intervals in the Cairo and adjacent region, including human habitats not marked as high impervious surface (Unmarked Habitat), human habitats marked as high impervious surface (Marked Habitat), barren areas with human habitats and vegetation (Barren) and vegetation areas such as croplands or grasslands (Vegetation).

\section{Discussion}

\subsection{Discussion of the Results of the SDG 6 Study}

This research investigated hydrological parameters related to water stress situations in the Nile Basin countries, especially highlighting the usage of EO to solve the spatial and temporal data shortage and inconsistency related to the renewable freshwater from both surface water and groundwater resources. The changing trends of multiple hydrological parameters related to the surface water resources and their relationships with groundwater has been demonstrated (Figures 3 and 4 ). The groundwater recharge from the surface water also has been shown in Figures 5 and 6 in the time-series and cross-correlation analysis. The impact on groundwater recharge under various climate change scenarios has been investigated by previous studies [42-44], which commonly concluded that, globally, the amount of groundwater is decreasing, especially in the Northern Africa and Middle East regions. In Figure 3, the decreasing trend of LWE in Egypt and part of Sudan confirms what was found in the previous study that the basin sinks with the negative water balance in the downstream Nile countries [45]. For the Nile Basin, our results of $\Delta S$ as P-ET-R show a slightly different pattern compared with what was presented in the previous study. This may be due to the choices of different hydrological datasets (e.g., Tropical Rainfall Measuring Mission (TRMM) vs. CHIRPS datasets for precipitation, Global Land Data Assimilation System (GLDAS) vs. FLDAS for runoff, Moderate Resolution Imaging Spectroradiometer (MODIS) vs. FLDAS for ET). As the main consumption of the freshwater, the agriculture sector consumes over $80 \%$ of the total water resources in Egypt [46]. Meanwhile, the abstraction from groundwater grows rapidly with the expansion of irrigation activities, industrialization and urbanization [46]. In Figure 3, the precipitation, ET and runoff are stable for the northern part of the Nile watershed but with decreasing LWE. In Figure 5, Egypt's LWE level hit the lowest in the year 2012 and recovered to nearly zero after the year 2016. These observations match the decreased FGWW from 2012 to 2017 reported in Table 2. Therefore, the loss of the groundwater is very likely due to overexploitation. Consequently, the decreasing LWE may correspond to the impacts of abstraction of groundwater to meet increasing agricultural and other needs. Moreover, this study also directly compared the P-ET-R monthly anomalies values and the LWE values through correlational analysis (Figure 6). The approach used both time series analysis, correlation maps (up to 3 months lags) to show the spatial water transport, and recharge pattern among different regions in the Nile watershed. 
In Figure 6, southern Egypt has shown a positive relationship between P-ET-R and LWE, indicating possible external groundwater recharge from the upstream water resources to Egypt since it is listed as the only country receiving external groundwater in the Nile Basin countries (Table 2). It is also noted that the magnitude of the P-ET-R is much larger for water-rich basins such as Amazon and Mekong than Nile [37]. The study validates the use of P-ET-R to show the spatial and temporal variability as it reflects the increase or decrease in the water storage in coordination with the GRACE dataset, especially for some countries such as Ethiopia, Sudan and South Sudan (Figure 5). Moreover, the accurate estimation of water stress situations is also significantly related to the freshwater withdrawn (TFWW) by all major sectors, as well as environmental water requirements (EFR). Table 2 shows that the missing TFWW data causes water stress unable to be calculated. Meanwhile, the unchanged EFR data indicates consistent environmental flow requirements between 2007 to 2017, which is questionable for the recent changes of their natural and social conditions (dams development, population growth, etc.). Therefore, the specific studies on collecting high-quality TFWW and EFR data are suggested to be undertaken for the actual report of water stress situations. The study of water stress also helps water resources management cooperation between Nile Basin countries in support of SDG Target 6.5 "implement integrated water resources management at all levels, including through transboundary cooperation as appropriate".

\subsection{Discussion of the Results of the SDG 11 Study}

For Indicator 11.3.1, the impervious surface maps generated from the research provides updated information of the land cover that can be used to monitor the population distribution and the quality of their settlement as a result of urban expansion of the selected countries (Figure 7). However, the model trained from the US data sources cannot identify some parts of the human habitats in Cairo and Khartoum as impervious surfaces. The optical spectral signatures in Figure 8 only show slightly differences between the marked and unmarked regions in terms of the confidence levels of the averaged surface reflectances, which cannot clearly discriminate different surface types. It is known that the model does not simply use the spectral differences as the parameters but also includes the imagery context or texture. Therefore, it is possible that the training data from US cities lack certain texture or types of impervious surface, which are common in Cairo or other cities. It is suggested that both unmarked regions in Cairo and Khartoum are the towns with similar constructions and homogeneous texture and materials. It is also found that for the entire Nile Delta region, many towns or villages are also classified as non-impervious surfaces (Figure 9 regions A-E), where the percentage value of impervious surfaces is even lower than surrounding crop fields (also seen in Figure 7). This indicates the some non-impervious surface regions are still human settlements, while the constructions are built by the permeable materials and occasionally shaded from higher vegetation (e.g., palm trees).

Additionally, for Indicator 11.1.1, the difference between the low-income community (rural and slum areas) (characterized with homogeneous houses and imagery textures) and high-income community (chartered with high urban greening and diverse buildings) can alter the model outputs. For instances, Figure 10 shows the classified impervious surface of Karachi, Pakistan, and its slum Orangi Town (red square region), which is regarded as the largest slum in the world with an estimated population from 1.5 to 2.4 million [47]. It is noted that the FCNN model shows more details of the distribution of the land cover than the MODIS product. However, the MODIS product classifies Orangi Town as impervious surface yet the model does not mark Orangi Town but marks the adjacent region with rich heterogeneous textures (right bottom corner cross the red line) as impervious surface. Orangi Town has houses of similar structure and homogeneous texture. It is reasonable to speculate that such typical texture of impervious surface, as well as the building materials of the houses and villages (such as sand, woods or mud) in the arid and semi-arid regions of Egypt and Pakistan are not typical and included in the US training datasets. However, such high-resolution impervious surface datasets are only limited in the US cities. This situation reflects a data inequality between developed and developing countries and that even the results of a modeling approach to help investigate the 
developing countries can be biased. Extensive model optimization and tuning is needed to effectively monitor the slums settlement.

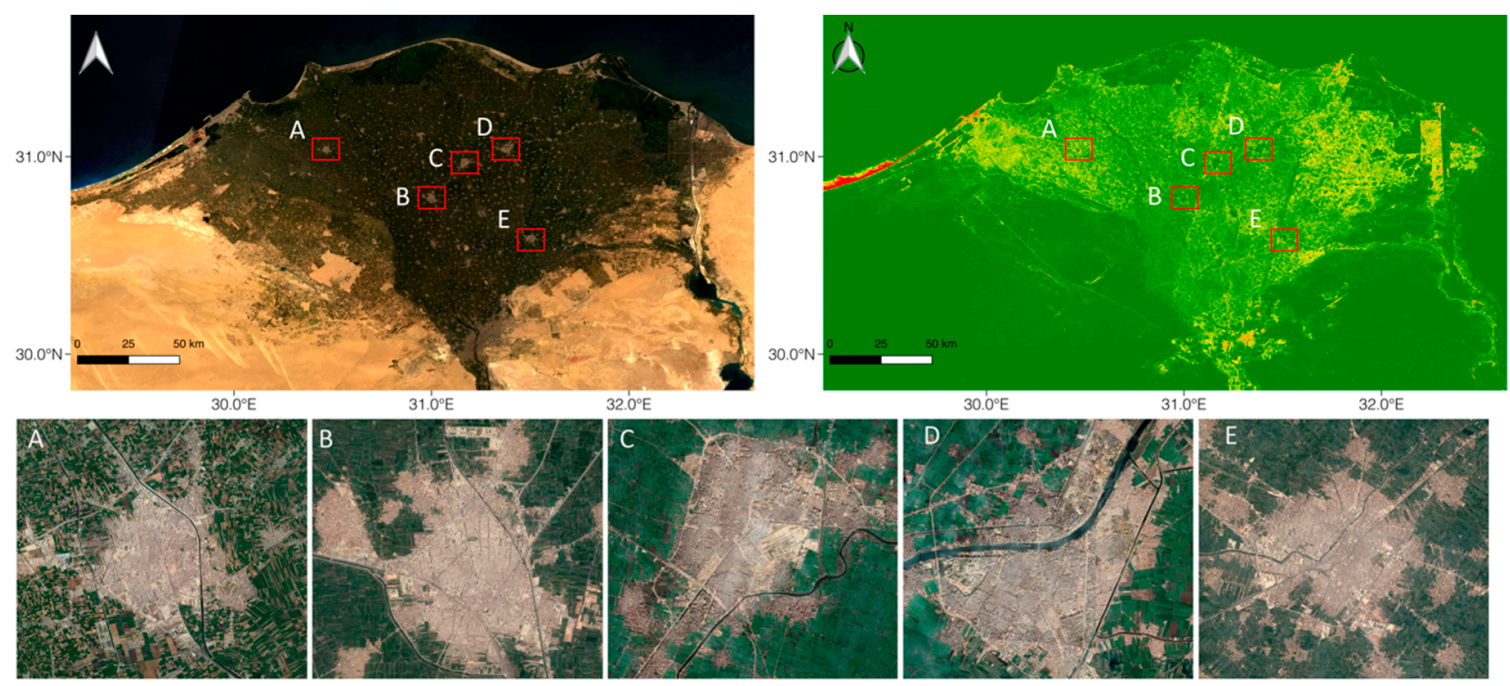

Figure 9. The Landsat- 8 true color composite image and corresponding impervious surface map in the year 2019 for the Nile Delta region with its unmarked towns (A-E) shown in the high-resolution satellite images in Google Map.
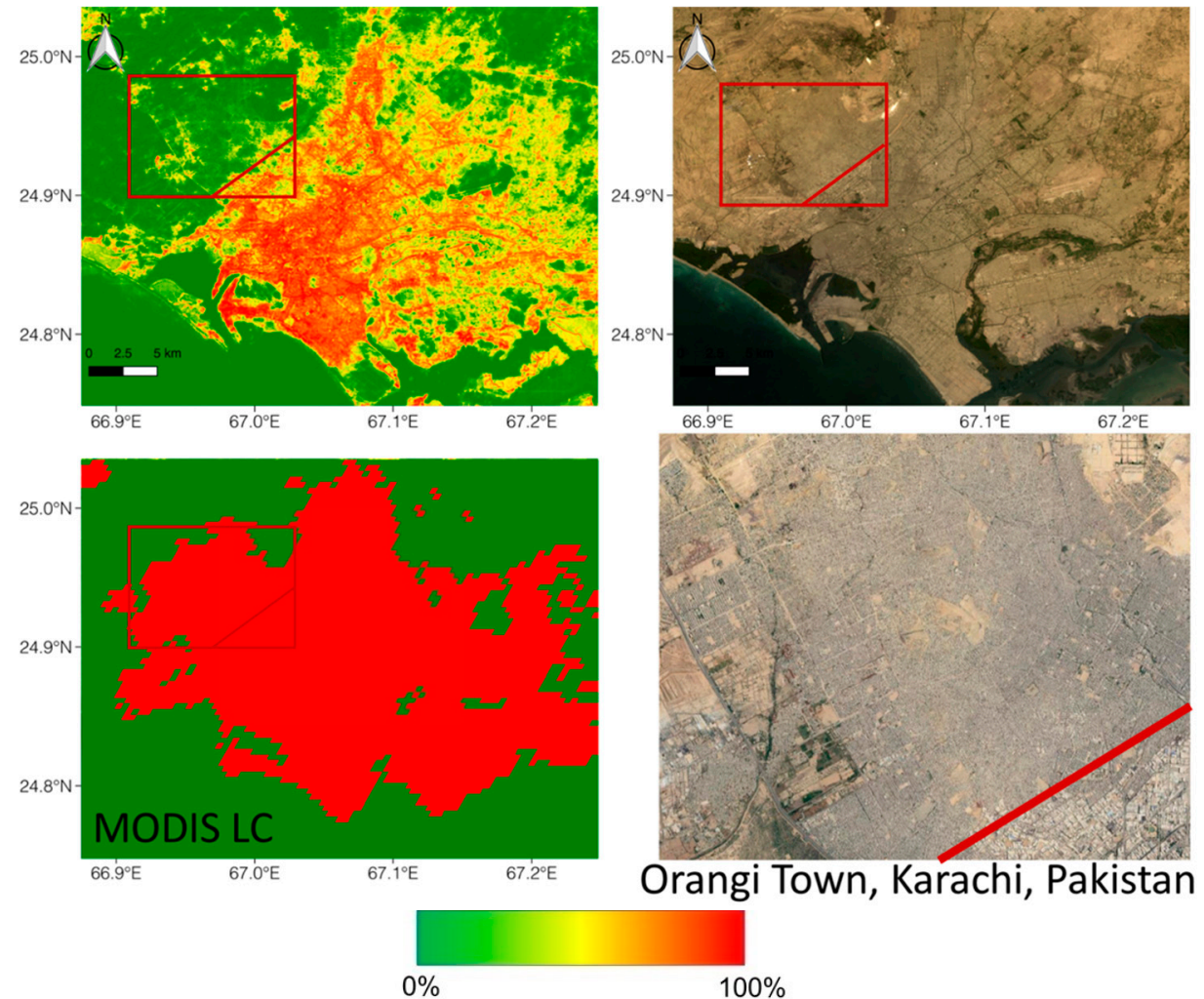

Figure 10. The Landsat- 8 true color composite image and corresponding impervious surface map in the year 2019 (first row) for the Karachi, Pakistan. Red line separates the marked high impervious region from the biggest slum named Orangi Town (red rectangle) shown in the high resolution satellite image in Google Map. The MODIS land cover type classification of urban and built-up lands of at least $30 \%$ impervious surface area are marked by the red region (second row left). (Source: NASA Land Processes Distributed Active Archive Center: https://lpdaac.usgs.gov/products/mcd12q1v006). 
At present, the most employed satellite-based global settlement datasets use either optical (e.g., the Global Human Settlement Layer (GHSL) [48], and the GLOBELAND30 (GLC30) [49]), or radar imagery (e.g., the Global Urban Footprint (GUF) [50]). However, the exclusive use of radar or optical imagery alone is limited by their sensitivity to different structures on the ground. For example, forested regions and areas with complex topography can be misclassified as settlements using radar imagery, while normally this does not occur with optical data; on the contrary, sand and bare soil regions tend to be wrongly categorized as settlements with optical data, whereas this does not occur with radar data [51]. To overcome this issues, the World Settlement Footprint (WSF)-2015 [51] was recently developed with jointly usage of both radar (Sentinel-1) and optical (Landsat-8) data, and shows higher accuracy and reliability than the aforementioned settlement datasets. The improvement of the impervious surface model is suggested from the methodology of WSF-2015 listed below:

1. It uses both optical and radar imagery for the model development. WSF-2015 processed multitemporal Sentinel-1 ( 107,000 scenes) radar and Landsat-8 ( 217,000 scenes) optical imagery, and has been validated against 900,000 samples labelled by crowdsourcing photointerpretation of high-resolution Google Earth imagery.

2. It improves feature extraction with multiple indices. In WSF-2015, multiple spectral indices were extracted from Landsat-8 imagery in the feature stack, including The Normalized Difference Built-Up Index (NDBI) [52], Normalized Difference Middle Infrared index (NDMIR) [53] and the Normalized Difference Vegetation Index (NDVI) [54], Modified Normalized Difference Water Index (MNDWI) [55], Normalized Difference Red Blue (NDRB) [56] and Normalized Difference Green Blue (NDGB) [56]. WSF-2015 used six computed temporal statistics, including maximum, minimum, mean, standard deviation, mean slope (i.e., the average absolute difference between consecutive items of the temporal series), as well as coefficient of variation (COV) and number of scenes, for the feature extraction from Sentinel-1 and Landsat- 8 indices.

3. It optimizes training sample selection criteria. WSF-2105 improved training sample selection process with a criteria took into account of the well-established Köppen Geiger scheme [57] for Landsat-8 imagery, as well as a knowledge-based criteria for Sentinel-1 of both ascending and descending scenes. It also masked bare rocks with higher slopes using digital elevation models (DEM) from the Shuttle Radar Topography Mission (SRTM) [58] and the Advanced Spaceborne Thermal Emission and Reflection Radiometer (ASTER) [59].

4. It adds post-processing for the classification results. WSF-2015 used different global and regional reference datasets for reference in the post-classification phrase. Then the final classification map was generated from the merger of both Landset- 8 and Sentinel-1 based classification maps that have been processed with object-based segmentation approaches.

In the model training experience of this study, the Google Cloud Platform (GCP) charged \$25.99 to generate the model within $31 \mathrm{~h}$. It is a relatively inexpensive for researchers with limited financial capacity, considering GCP also provides $\$ 300$ credit for new users which covers all the cost. Our case here shows an example of tackling the data/methodology bottleneck of SDG studies with EO data and cloud computing in an economical (free of charge) approach. Therefore, further advancement and applications of EO and cloud computing should be explored to empower the effective assessment, data availability and monitoring of each and all SDG targets and indicators essential to ensure the achievement of SDGs.

The methods and tools of this study are provided in the Supplementary Materials (S1-S6) that can be used for various topics in different regions.

\section{Conclusions}

This study presents the EO and cloud computing solutions to support the SDG 6 "clean water and sanitation" and SDG 11 "sustainable cities and communities" in the seven Nile watershed countries. Multiple SDG indictors are studied including: the water stress (6.4.2), land use and urban 
development under population growth (11.3.1) and monitoring slums (11.1.1). The results clearly show the connections between multiple hydrological parameters and spatial/temporal groundwater recharge patterns in the region. Moreover, an advanced deep-learning impervious surface classifier using fully convolution neural networks (FCNN) was trained on top of the cloud platform to monitor the urbanization procedure in the selected five cities during the period 2013 to 2019. Clear urban expansions are observed in the developed regions while the classifier is limited to identify slums/rural areas and their changes. This may due to the biases introduced for the difference between training data from developed countries (i.e., United States) and developing countries in the Nile watershed. In addition, this study shows an economical approach of using the open-and-free EO data and cloud computing to tackle the data/methodology bottleneck of developing countries in SDG studies. Therefore, the authors suggest future North-South and South-South cooperation to solve the data inequality among countries, as well as the development of methods to fully use the advancement of EO and cloud computing to achieve SDGs.

Supplementary Materials: The following are available online at: S1. The workflow of the FCNN model development is available in the Colab notebooks: https:/colab.research.google.com/github/google/earthengineapi/blob/master/python/examples/ipynb/UNET_regression_demo.ipynb;https://colab.research.google.com/github/ google/earthengine-api/blob/master/python/examples/ipynb/AI_platform_demo.ipynb; S2. The sampling and area calculator in GEE: https://code.earthengine.google.com/86a784f23ab66285fb9521e156b044c2; S3. The correlation analysis of water: https://code.earthengine.google.com/4e89f2e9121803849a5cb9f502636c19; S4. The correlation analysis of anomalies: https://code.earthengine.google.com/c60775fe09880ad6dda77e5bd0021bb1; S5. The harmonic analysis of water: https://code.earthengine.google.com/d561453ad8888f2a1746b61662916803; S6. The impervious surface classification: https://code.earthengine.google.com/99cffbe8d90bc4b2d9f43e463bc83a68.

Author Contributions: Conceptualization, H.E.-A., T.P. and W.L.; data analysis, W.L. and V.L.; funding acquisition, H.E.-A. and D.S.; methodology, H.E.-A., W.L. and V.L.; validation, W.L. and V.L.; writing-original draft, W.L.; writing-review and editing, H.E.-A., W.L., V.L., T.P. and D.S. All authors have read and agreed to the published version of the manuscript.

Funding: The data processing and analysis of the study is supported by the Samueli Laboratory in Computational Sciences in the Schmid College of Science and Technology, Chapman University.

Acknowledgments: The authors would like to thank the Nicholas Clinton, Christopher Brown from Google Earth Engine team for the updated integration API with Google Cloud's AI Platform to connect Earth Engine data to the TensorFlow models, and their kind work of tutorials and help to the geoscience community. The first author acknowledge the support from the Earth Systems Science and Data Solutions (EssDs) Lab and from Computational and Data Sciences Graduate Program, Schmid College of Science and Technology, Chapman University.

Conflicts of Interest: The authors declare no conflict of interest.

\section{References}

1. Liu, S.; Lu, P.; Liu, D.; Jin, P.; Wang, W. Pinpointing the sources and measuring the lengths of the principal rivers of the world. Int. J. Digit. Earth 2009, 2, 80-87. [CrossRef]

2. Elsanabary, M.H.M.M. Teleconnection, Modeling, Climate Anomalies Impact and Forecasting of Rainfall and Streamflow of the Upper Blue Nile River Basin. Ph.D. Thesis, University of Alberta, Edmonton, AB, Canada, 2012. [CrossRef]

3. Bakenaz, A. Zeidan Water Conflicts in the Nile River Basin: Impacts on Egypt Water Resources Management and Road Map. 2015. [CrossRef]

4. Investopedia How Does Industrialization Lead to Urbanization? Available online: https://www.investopedia. com/ask/answers/041515/how-does-industrialization-lead-urbanization.asp (accessed on 31 March 2020).

5. Refugees and Asylum-Seekers from South Sudan. Refugee Situations. Available online: http://data.unhcr. org/SouthSudan/regional.php (accessed on 6 October 2019).

6. Eltayeb, G.E. Understanding slums: The case of Khartoum, Sudan; UN-HABITAT Case Studies: London, UK, 2003; pp. 1-20.

7. United Nations General Assembly. Transforming Our World: The 2030 Agenda for Sustainable Development; A/RES/70/1; In Proceedings of the 4th Plenary Meeting, New York, NY, USA. 2015. Available online: http://www.un.org/ga/search/view_doc.asp?symbol=A/RES/70/1\&Lang=E (accessed on 26 January 2019). 
8. United Nations General Assembly. Work of the Statistical Commission Pertaining to the 2030 Agenda for Sustainable Development. A/RES/71/313; Seventy-first Session, NY, USA. 2017. Available online: https://undocs.org/A/RES/71/313 (accessed on 26 January 2019).

9. United Nations. The Sustainable Development Goals Report 2019. Available online: https://unstats.un.org/ sdgs/report/2019 (accessed on 26 October 2019).

10. Chinese Academy of Sciences. Big Earth Data in Support of the Sustainable Development Goals. Available online: http://www.xinhuanet.com/english/download/BigEarthDataSupportSDGs.pdf (accessed on 26 September 2019).

11. Technology Facilitation Mechanism. Available online: https://sustainabledevelopment.un.org/tfm (accessed on 6 October 2019).

12. Transforming Our World: The 2030 Agenda for Sustainable Development. In A New Era in Global Health; Rosa, W., Ed.; Springer Publishing Company: New York, NY, USA, 2017; ISBN 978-0-8261-9011-6.

13. Group on Earth Observations. Earth Observations in Support of the 2030 Agenda for Sustainable Development; Japan Aerospace Exploration Agency: Tokyo, Japan, 2017.

14. Li, W.; El-Askary, H.; Qurban, M.A.; Li, J.; ManiKandan, K.P.; Piechota, T. Using multi-indices approach to quantify mangrove changes over the Western Arabian Gulf along Saudi Arabia coast. Ecol. Indic. 2019, 102, 734-745. [CrossRef]

15. Li, W.; El-Askary, H.; Qurban, M.; Proestakis, E.; Garay, M.; Kalashnikova, O.; Amiridis, V.; Gkikas, A.; Marinou, E.; Piechota, T.; et al. An Assessment of Atmospheric and Meteorological Factors Regulating Red Sea Phytoplankton Growth. Remote Sens. 2018, 10, 673. [CrossRef]

16. Li, W.; El-Askary, H.; ManiKandan, K.; Qurban, M.; Garay, M.; Kalashnikova, O. Synergistic Use of Remote Sensing and Modeling to Assess an Anomalously High Chlorophyll-a Event during Summer 2015 in the South Central Red Sea. Remote Sens. 2017, 9, 778. [CrossRef]

17. Kim, S.-R.; Prasad, A.K.; El-Askary, H.; Lee, W.-K.; Kwak, D.-A.; Lee, S.-H.; Kafatos, M. Application of the Savitzky-Golay Filter to Land Cover Classification Using Temporal MODIS Vegetation Indices. Photogramm. Eng. Remote Sens. 2014, 80, 675-685. [CrossRef]

18. Le, J.A.; El-Askary, H.M.; Allali, M.; Struppa, D.C. Application of recurrent neural networks for drought projections in California. Atmos. Res. 2017, 188, 100-106. [CrossRef]

19. Gorelick, N.; Hancher, M.; Dixon, M.; Ilyushchenko, S.; Thau, D.; Moore, R. Google Earth Engine: Planetary-scale geospatial analysis for everyone. Remote Sens. Environ. 2017, 202, 18-27. [CrossRef]

20. Donchyts, G.; Baart, F.; Winsemius, H.; Gorelick, N.; Kwadijk, J.; Van de Giesen, N. Earth's surface water change over the past 30 years. Nat. Clim. Chang. 2016, 6, 810-813. [CrossRef]

21. El-Askary, H.M.; Li, W.; El-Nadry, M.; Awad, M.; Mostafa, A.R. Strong Interactions Indicated Between Dust Aerosols and Precipitation Related Clouds in the Nile Delta. In Advances in Remote Sensing and Geo Informatics Applications; El-Askary, H.M., Lee, S., Heggy, E., Pradhan, B., Eds.; Springer International Publishing: Cham, Switzerland, 2019; pp. 3-6. ISBN 978-3-030-01439-1.

22. El-Nadry, M.; Li, W.; El-Askary, H.; Awad, M.A.; Mostafa, A.R. Urban Health Related Air Quality Indicators over the Middle East and North Africa Countries Using Multiple Satellites and AERONET Data. Remote Sens. 2019, 11, 2096. [CrossRef]

23. Li, W.; Ali, E.; Abou El-Magd, I.; Mourad, M.M.; El-Askary, H. Studying the Impact on Urban Health over the Greater Delta Region in Egypt Due to Aerosol Variability Using Optical Characteristics from Satellite Observations and Ground-Based AERONET Measurements. Remote Sens. 2019, 11, 1998. [CrossRef]

24. Sazib, N.; Mladenova, I.; Bolten, J. Leveraging the Google Earth Engine for Drought Assessment Using Global Soil Moisture Data. Remote Sens. 2018, 10, 1265. [CrossRef] [PubMed]

25. Li, W.; El-Askary, H.M.; Qurban, M.; Allali, M.; Manikandan, K.P. On the Drying Trends Over the MENA Countries Using Harmonic Analysis of the Enhanced Vegetation Index. In Advances in Remote Sensing and Geo Informatics Applications; El-Askary, H.M., Lee, S., Heggy, E., Pradhan, B., Eds.; Springer International Publishing: Cham, Switzerland, 2019; pp. 243-245. ISBN 978-3-030-01439-1.

26. AQUASTAT Database. Available online: http://www.fao.org/nr/water/aquastat/data/query/index.html? lang=en (accessed on 8 April 2020).

27. Bolten, J.D.; Crow, W.T. Improved prediction of quasi-global vegetation conditions using remotely-sensed surface soil moisture: Improved prediction of vegetation. Geophys. Res. Lett. 2012, 39. [CrossRef] 
28. Bolten, J.D.; Crow, W.T.; Zhan, X.; Jackson, T.J.; Reynolds, C.A. Evaluating the Utility of Remotely Sensed Soil Moisture Retrievals for Operational Agricultural Drought Monitoring. IEEE J. Sel. Top. Appl. Earth Obs. Remote Sens. 2010, 3, 57-66. [CrossRef]

29. Mladenova, I.E.; Bolten, J.D.; Crow, W.T.; Anderson, M.C.; Hain, C.R.; Johnson, D.M.; Mueller, R. Intercomparison of Soil Moisture, Evaporative Stress, and Vegetation Indices for Estimating Corn and Soybean Yields Over the U.S. IEEE J. Sel. Top. Appl. Earth Obs. Remote Sens. 2017, 10, 1328-1343. [CrossRef]

30. Kerr, Y.H.; Levine, D. Foreword to the Special Issue on the Soil Moisture and Ocean Salinity (SMOS) Mission. IEEE Trans. Geosci. Remote Sens. 2008, 46, 583-585. [CrossRef]

31. Funk, C.; Peterson, P.; Landsfeld, M.; Pedreros, D.; Verdin, J.; Shukla, S.; Husak, G.; Rowland, J.; Harrison, L.; Hoell, A.; et al. The climate hazards infrared precipitation with stations-A new environmental record for monitoring extremes. Sci. Data 2015, 2, 150066. [CrossRef]

32. NASA GSFC Hydrological Sciences Laboratory (HSL). FLDAS Noah Land Surface Model L4 Global Monthly $0.1 \times 0.1$ degree (MERRA-2 and CHIRPS). 2018. Available online: https://disc.gsfc.nasa.gov/datasets/FLDAS_ NOAH01_C_GL_M_001/summary (accessed on 1 February 2020).

33. McNally, A.; Arsenault, K.; Kumar, S.; Shukla, S.; Peterson, P.; Wang, S.; Funk, C.; Peters-Lidard, C.D.; Verdin, J.P. A land data assimilation system for sub-Saharan Africa food and water security applications. Sci. Data 2017, 4, 170012. [CrossRef]

34. Landerer, F.W.; Swenson, S.C. Accuracy of scaled GRACE terrestrial water storage estimates: Accuracy of GRACE-TWS. Water Resour. Res. 2012, 48. [CrossRef]

35. Swenson, S.C. GRACE Monthly Land Water Mass Grids NETCDF RELEASE 5.0. Ver. 5.0; PO.DAAC: Pasadena, CA, USA, 2012.

36. Swenson, S.; Wahr, J. Post-processing removal of correlated errors in GRACE data. Geophys. Res. Lett. 2006, 33, L08402. [CrossRef]

37. Lakshmi, V.; Fayne, J.; Bolten, J. A comparative study of available water in the major river basins of the world. J. Hydrol. 2018, 567, 510-532. [CrossRef]

38. Yang, L.; Jin, S.; Danielson, P.; Homer, C.; Gass, L.; Bender, S.M.; Case, A.; Costello, C.; Dewitz, J.; Fry, J.; et al. A new generation of the United States National Land Cover Database: Requirements, research priorities, design, and implementation strategies. ISPRS J. Photogramm. Remote Sens. 2018, 146, 108-123. [CrossRef]

39. Sun, Z.; Xu, R.; Du, W.; Wang, L.; Lu, D. High-Resolution Urban Land Mapping in China from Sentinel 1A/2 Imagery Based on Google Earth Engine. Remote Sens. 2019, 11, 752. [CrossRef]

40. Landsat-8 image courtesy of the U.S. Geological Survey. Available online: https://www.usgs.gov/centers/ eros/data-citation?qt-science_support_page_related_con=0\#qt-science_support_page_related_con (accessed on 19 February 2020).

41. Long, J.; Shelhamer, E.; Darrell, T. Fully convolutional networks for semantic segmentation. In Proceedings of the IEEE Conference on Computer Vision and Pattern Recognition (CVPR), Boston, MA, USA, 7-12 June 2015; IEEE: Piscataway, NJ, USA, 2015; pp. 3431-3440.

42. Herrera-Pantoja, M.; Hiscock, K.M. The effects of climate change on potential groundwater recharge in Great Britain. Hydrol. Process. 2008, 22, 73-86. [CrossRef]

43. Taylor, R.G.; Scanlon, B.; Döll, P.; Rodell, M.; Van Beek, R.; Wada, Y.; Longuevergne, L.; Leblanc, M.; Famiglietti, J.S.; Edmunds, M.; et al. Ground water and climate change. Nat. Clim. Chang. 2013, 3, 322-329. [CrossRef]

44. Scanlon, B.R.; Keese, K.E.; Flint, A.L.; Flint, L.E.; Gaye, C.B.; Edmunds, W.M.; Simmers, I. Global synthesis of groundwater recharge in semiarid and arid regions. Hydrol. Process. 2006, 20, 3335-3370. [CrossRef]

45. Senay, G.B.; Velpuri, N.M.; Bohms, S.; Demissie, Y.; Gebremichael, M. Understanding the hydrologic sources and sinks in the Nile Basin using multisource climate and remote sensing data sets. Water Resour. Res. 2014, 50, 8625-8650. [CrossRef]

46. Mahmoud, M.A. Groundwater and Agriculture in the Nile Delta. In Groundwater in the Nile Delta; Negm, A.M., Ed.; Springer International Publishing: Cham, Switzerland, 2017; Volume 73, pp. 141-157. ISBN 978-3-319-94282-7.

47. U.S NEWS. 8 Cities with the World's Largest Slums. Available online: https://www.usnews.com/news/cities/ articles/2019-09-04/the-worlds-largest-slums (accessed on 26 October 2019).

48. Esch, T.; Heldens, W.; Hirner, A.; Keil, M.; Marconcini, M.; Roth, A.; Zeidler, J.; Dech, S.; Strano, E. Breaking new ground in mapping human settlements from space-The Global Urban Footprint. ISPRS J. Photogramm. Remote Sens. 2017, 134, 30-42. [CrossRef] 
49. Corbane, C.; Pesaresi, M.; Kemper, T.; Politis, P.; Florczyk, A.J.; Syrris, V.; Melchiorri, M.; Sabo, F.; Soille, P. Automated global delineation of human settlements from 40 years of Landsat satellite data archives. Big Earth Data 2019, 3, 140-169. [CrossRef]

50. Chen, J.; Chen, J.; Liao, A.; Cao, X.; Chen, L.; Chen, X.; He, C.; Han, G.; Peng, S.; Lu, M.; et al. Global land cover mapping at $30 \mathrm{~m}$ resolution: A POK-based operational approach. ISPRS J. Photogramm. Remote Sens. 2015, 103, 7-27. [CrossRef]

51. Marconcini, M.; Metz-Marconcini, A.; Üreyen, S.; Palacios-Lopez, D.; Hanke, W.; Bachofer, F.; Zeidler, J.; Esch, T.; Gorelick, N.; Kakarla, A.; et al. Outlining where humans live-The World Settlement Footprint 2015. arXiv 2019, arXiv:1910.12707.

52. Zha, Y.; Gao, J.; Ni, S. Use of normalized difference built-up index in automatically mapping urban areas from TM imagery. Int. J. Remote Sens. 2003, 24, 583-594. [CrossRef]

53. Lu, D.; Mausel, P.; Brondízio, E.; Moran, E. Relationships between forest stand parameters and Landsat TM spectral responses in the Brazilian Amazon Basin. Forest Ecol. Manag. 2004, 198, 149-167. [CrossRef]

54. Rouse, J.; Haas, R.; Schell, J.; Deering, D. Monitoring vegetation systems in the Great Plains with ERTS. NASA Spec. Publ. 1974, 351, 309.

55. $\mathrm{Xu}, \mathrm{H}$. Modification of normalised difference water index (NDWI) to enhance open water features in remotely sensed imagery. Int. J. Remote Sens. 2006, 27, 3025-3033. [CrossRef]

56. Zhou, Y.; Yang, G.; Wang, S.; Wang, L.; Wang, F.; Liu, X. A new index for mapping built-up and bare land areas from Landsat-8 OLI data. Remote Sensing Lett. 2014, 5, 862-871. [CrossRef]

57. Peel, M.C.; Finlayson, B.L.; McMahon, T.A. Updated world map of the Köppen-Geiger climate classification. Hydrol. Earth Syst. Sci. 2007, 11, 1633-1644. [CrossRef]

58. Farr, T.G.; Rosen, P.A.; Caro, E.; Crippen, R.; Duren, R.; Hensley, S.; Kobrick, M.; Paller, M.; Rodriguez, E.; Roth, L.; et al. The Shuttle Radar Topography Mission. Rev. Geophys. 2007, 45, RG2004. [CrossRef]

59. Abrams, M.; Bailey, B.; Tsu, H.; Hato, M. The ASTER Global DEM. Photogramm. Eng. Remote Sens. 2010, $76,344-348$.

(C) 2020 by the authors. Licensee MDPI, Basel, Switzerland. This article is an open access article distributed under the terms and conditions of the Creative Commons Attribution (CC BY) license (http://creativecommons.org/licenses/by/4.0/). 